\title{
A model study of Luzon Cold Eddies in the northern South China
}

\section{Sea}

\author{
Yinghui He ${ }^{\text {a }}$, Shuqun Cai ${ }^{\text {a, }}$, Dongxiao Wang ${ }^{\text {a }}$, Jianling $\mathrm{He}^{\text {a, b }}$ \\ ${ }^{a}$ State Key Laboratory of Tropical Oceanography, South China Sea Institute of \\ Oceanology, Chinese Academy of Sciences, Guangzhou 510301, China \\ ${ }^{b}$ University of Chinese Academy of Sciences, Beijing, 100049, China
}

Corresponding author: Dr. Shuqun Cai

Address: 164 West Xingang Road, 510301, Guangzhou, P.R. China

Email: caisq@scsio.ac.cn

Tel: 0086-20-89023186 


\begin{abstract}
:
A variable-grid global ocean circulation model (MITgcm) was employed to study the effects of wind and Kuroshio intrusion on the Luzon Cold Eddies (LCEs) in the northern South China Sea (SCS). Study findings showed that there are two cold eddies northwest of the Luzon Island. The cold eddies above 300m and below 500m depth are referred to as the upper and lower layer LCE, respectively, based on their different generation sites, properties and dynamic mechanisms in these layers. In this study, the upper layer LCE was mainly induced by the winter wind stress curl in the SCS and generated northwest of the Luzon Island in late November, but it may have been weakened by the Kuroshio intrusion. It moved northwestward and decayed at about $\left(115^{\circ} \mathrm{E}, 20^{\circ} \mathrm{N}\right)$ in late June. The center of the upper layer LCE tilted westward with increasing depth until March. The vorticity intensity of the upper layer LCE peaked in December to January and generally decreased with depth. The contributions of both wind stress curl and Kuroshio intrusion to the generation of the lower layer LCE were roughly equal. The lower layer LCE originated from a cold eddy, which moved westward from the Luzon Strait in August through October and then intensified by wind stress curl. Subsequently, it moved westward with a slight southward migration and finally decayed near the Xisha Islands in April to May. Its amplitude and radius reached a maximum around December, while the vorticity intensity peaked in January to February.
\end{abstract}

Key words: Luzon Cold Eddy; Vertical structure; Eddy energy; Numerical model; South China Sea 


\section{Introduction}

The South China Sea (SCS) circulation has been extensively studied in recent decades (e.g., Wyrtki, 1961; Qu, 2000). In summer, a weak cyclonic gyre is in the northern SCS but an anti-cyclonic gyre occupies the southern SCS (Xu et al., 1982). In winter, a cyclonic gyre occupies the whole SCS, with its center located northwest of the Luzon Island (Qu,2000; Liu et al., 2008). As the main component of the SCS winter cyclonic gyre, the Luzon Cold Eddy (LCE) has been identified in several studies (Shaw et al., 1996; Qu, 2000; Yang and Liu, 2003; Metzger, 2003). Using the Princeton Ocean Model (POM) to study the formation mechanism of the LCE, Yang and Liu (2003) suggested that the LCE can be identified as a forced Rossby wave with a negative sea surface height anomaly (SSHA) in winter; this cold eddy is generated by wind stress, while the Kuroshio intrusion is of minor importance. By comparing the LCE generated from the Navy Layered Ocean Model (NLOM) driven by three different atmospheric products, Metzger (2003) argued that the LCE is controlled by a positive wind stress curl west of the Luzon Island. Wang et al. (2008) also indicated that the orographic wind jets associated with the northeaster winter monsoon off the northwester Luzon Island play important roles in the origin of the LCE. Based on altimeter data, Sun and Liu (2011) found that the winter LCE may be composed of two cyclonic eddies. One is located west of Luzon Island, whose generation is associated with the wind stress curl and only exists in the winter; the other is located off the western Luzon Island, and may be induced by the Kuroshio intrusion.

Altimeter data are also widely used in the identification and statistics of mesoscale eddies in the SCS. Based on these data, Wang et al. (2003) found that many cyclonic and anti-cyclonic eddies are generated from the northwest of Luzon 
Island, and they may be caused by the positive vorticity advection from the Kuroshio front (Liu and Su, 1992) and the local positive wind stress curl (Qu et al., 2000). Xiu et al. (2010) quantified eddy activities in the SCS from a physical-biogeochemical model, in which results were compared with those derived from the altimeter data. Chen et al. (2011) also identified eddies in the SCS-based altimeter data from 1992-2009 and analyzed their effects on the thermocline combined with the Argo temperature profile data.

In recent years, the vertical structure of mesoscale eddies has received wide attention. For example, by using in-situ observational current and other hydrographical data, Hu et al. (2011) examined the three-dimensional structure of a cold eddy southeast of Vietnam and found that this cold eddy extended downward for more than $250 \mathrm{~m}$ with a vertically tilted central axis. Nan et al. (2011) identified three anti-cyclonic eddies from both altimeter data and in-situ measurements in the northern SCS, finding that the effect of eddies can reach SCS deep water. Dong et al. (2012) analyzed a three-dimensional dataset from a numerical product of the oceanic circulation in the Southern California Bight and identified three types of eddies based on shape: bowl, lens and cone.

Although the lifetime and track of the LCE have been studied to date, the three-dimensional structure of the LCE and its evolution remain unknown and therefore are the focus of this study. The impacts of the Kuroshio intrusion and wind field on the LCE are also further investigated. A variable-grid global ocean circulation model, the Massachusetts Institute of Technology General Circulation Model (MITgcm; Marshall et al., 1997), was used for this purpose. The paper is organized as follows. A brief description of the model setup is presented in section 2 , followed by an overview 
of the model validation in section 3 , analysis of modeled results in section 4 , and conclusions of this study in section 5 .

\section{Model description}

The MITgcm is a quasi-global model, with its northern and southern boundaries closed at $65.5^{\circ} \mathrm{N}$ and $75.4725^{\circ} \mathrm{S}$, respectively (Fig.1a). To resolve the circulation in the SCS (Fig.1b), this study used zonal grid spacing of $1 / 6^{\circ}$ for the longitude from $99^{\circ} \mathrm{E}$ to $146^{\circ} \mathrm{E}$ and meridional spacing of $1 / 6^{\circ} \cos \varphi$ for the latitude from $20^{\circ} \mathrm{S}$ to $50^{\circ} \mathrm{N}$, where $\varphi$ represents the latitude. A buffering zone was located between the fine and coarse grids, in which the resolution increased exponentially to $1^{\circ}$, i.e., the zonal resolution increased exponentially from $1 / 6^{\circ}$ to $1^{\circ}$ within $78^{\circ} \mathrm{E}-99^{\circ} \mathrm{E}$ and $146^{\circ} \mathrm{E}-167^{\circ} \mathrm{E}$, and the meridional resolution increased exponentially from $1 / 6^{\circ} \cos \varphi$ to $1^{\circ} \cos \varphi$ within $20^{\circ} \mathrm{S}-37.6^{\circ} \mathrm{S}$ and $50^{\circ} \mathrm{N}-61.2^{\circ} \mathrm{N}$. For the remainder, the resolution is $1^{\circ}$. There were 25 vertical levels, with 13 levels in the upper 530m (Table 1). The bottom topography was taken from ETOPO $2^{1}$ and then the depth data were interpolated to each grid.

The initial temperature and salinity data were derived by an interpolation of the World Ocean Atlas 2001 (WOA01) annual climatological data (Boyer et al., 2002; Stephens et al., 2002). The model used the Leith viscosity parameterization (Leith, 1996) for the eddy simulation and the nonlocal K-profile parameterization scheme (Large et al., 1994) for the vertical mixing. It was first spun up by a 10-year integration with the QuikSCAT annual climatology (averaged from 2000 to 2007) wind stress to

\footnotetext{
${ }^{1}$ ETOPO2v2 2-Minute Gridded Global Relief Data, National Geophysical Data Center, National Oceanic and Atmospheric Administration, U.S. Dept. of Commerce, http://www.ngdc.noaa.gov/mgg/global/etopo2.html.
} 
reach a stationary annual circulation field. At this stage, the sea surface temperature (SST) and sea surface salinity (SSS) were restored to the WOA01 annual climatology, with a restoring timescale of 60 and 180 days, respectively. Then the model was continuously driven by the QuikSCAT monthly climatological wind stress for another 90 years, and the SST and SSS were restored to the WOA01 monthly climatology, with a restoring timescale of 30 days in order to reflect the 100-year spin-up state.

Four experiments (Exp.1-4) based on the 100-year spin-up state were carried out (Table 2). The control experiment (Exp.1) was run continuously for six years with the QuikSCAT monthly climatological wind forcing. To address the impact of local wind stress on the LCE, Exp.2 was the same as Exp.1 except that the wind stress in the SCS (Fig.1c) was set to zero. Exp.3 was the same as Exp.2 except that a uniform, monthly and spatially averaged wind stress field was imposed on the SCS (Fig.1c) so that the wind stress curl still equals 0. Both in Exp.2 and Exp.3, a buffer zone with two degrees width was set between the SCS and its external domain, where the wind stress gradually changes to that in the control run. Exp.4 was the same as Exp.1 except that the Luzon Strait was blocked (Fig.1c). Exps. 2 and 3 were designed to investigate the monsoon impacts, while Exp. 4 was intended to investigate the Kuroshio intrusion effects on the LCE. In each experiment, the model outputted 15-day averaged results over the last year for further analyses.

\section{Model validation}

The AVISO (Archiving, Validation and Interpretation of Satellite Oceanographic data) satellite altimeter absolute dynamic topography (ADT) data are used to validate the model results. The monthly climatology of ADT data from January 2000 to 
December 2007 is calculated to compare with the corresponding modeled result in Exp.1. As shown in Fig.2, the modeled circulation structure is basically similar to that from the satellite altimeter. For example, in March, a cyclonic eddy, typically known as the traditional LCE, is located northwest of the Luzon Island, while an anti-cyclonic eddy is located east of the Indochinese peninsula. After impinging the Philippine coast, the North Equatorial Current (NEC) bifurcates into the southward flowing Mindanao Current and the northward flowing Kuroshio, with the bifurcation latitude of NEC at about $13.2^{\circ} \mathrm{N}$. In June, an anti-cyclonic gyre occupies the SCS basin, and the NEC bifurcates at about $12.6^{\circ} \mathrm{N}$. In September, a dipole structure with a cyclonic eddy in the north and an anti-cyclonic one in the south is located east of the Indochinese peninsula, and the NEC bifurcates at about $13.6^{\circ} \mathrm{N}$. In December, a cyclonic gyre occupies the SCS basin, the LCE is located west of the Luzon Island and the NEC bifurcates at about $13.7^{\circ} \mathrm{N}$. The correlation coefficient of the modeled SSHA with AVISO SSHA, which is spatially averaged in box $\left(117^{\circ}-120^{\circ} \mathrm{E}, 17-20^{\circ} \mathrm{N}\right.$, hatched area in Fig.1c) where the LCE is generated, reaches 0.996.

Fig. 3 shows the vertical profile of the potential temperature anomalies in March, June, September and December at $18^{\circ} \mathrm{N}$ from WOA2009 and Exp.1. Herein, the anomaly is defined as the current state minus the annual mean state. Fig.3a indicates that the large temperature anomaly $\left(\left|\theta_{a}\right|>0.6\right)$ almost occurs at a depth above $300 \mathrm{~m}$. In the upper layer, cold temperature anomalies dominate west of the Luzon in December to March, while warm temperature anomalies dominate east of the continental slope along the SCS western boundary. The opposite temperature anomalies occur from June to October. In the lower layer, cold anomalies dominate the east of $113^{\circ} \mathrm{E}$ in December to March, while warm anomalies dominate this area from June to September. The above phenomena are simulated well in Exp.1, except that in 
December the depth of thermocline in the model is shallower than that in the WOA2009 data, which may be due to the unrealistic parameterization scheme of vertical mixing in the model. In view of the limited space resolution and the random factors in the WOA dataset, more details are discussed following the model results.

Overall, although there are some differences in magnitude between the satellite altimeter data and the modeled results, the monthly climatological circulation in the SCS and the Northwest Pacific can be well simulated by the model. The vertical structure pattern in the control run is quite similar to the WOA2009 data except in shallow water. Considering that the impact of an eddy can reach several hundred to a thousand meters in depth, it is credible to use the modeled results to further study the properties and dynamic mechanisms of the LCE.

\section{Results and discussion}

\subsection{Properties of the LCE}

The SSHA data have been widely used in the identification of eddies (e.g., Wang et al., 2003; Yang et al., 2013). The location of the local SSHA minimum or maximum is usually defined as the center of a cyclonic or anti-cyclonic eddy, respectively. The outermost closed SSHA contour, embedding only the considered center, corresponds to the eddy edge. Consistent with Chelton et al. (2011), the LCE radius at a depth is defined as the radius of the circle that has the same area as the region within the LCE perimeter that is identified at this depth. Fig.4 shows the spatiotemporal variability of the LCE, which is identified from the modeled SSHA. In this study, the LCE is generated off the western Luzon Island in November, then it 
moves northwestward and its radius increases until April. Subsequently, the eddy begins to weaken gradually and finally decays at about $\left(115.5^{\circ} \mathrm{E}, 20^{\circ} \mathrm{N}\right)$ in June. The AVISO monthly climatological sea level anomalies (SLA) are also shown in Fig.4 to validate the modeled LCE. Although the radius of the modeled LCE peaks in March to April, the LCE is typically weak; conversely, the radius of the LCE is relatively small in January, when the LCE is the strongest. A similar situation is observed in AVISO data. As the SLA climatology is averaged for several years, the eddy centers (i.e,. local SLA extreme point) are scattered at different points. As such, eddies identified from the SLA have lower amplitudes and the eddies margins are not as smooth as those in the modeled results. Nevertheless, despite a slight discrepancy of some eddy positions and SSH magnitudes, our modeled results generally agree with those obtained from AVISO data.

The cyclonic eddy is often accompanied by a subsurface cold core. To obtain the vertical structure of the LCE, this work detects the boundary of the LCE at different depths using the modeled potential temperature anomaly data, measured as the transient potential temperature minus annual mean potential temperature. The cold eddy center in each layer is identified at the position with a local minimum temperature anomaly, and the domain of the eddy in each layer is considered as the area surrounded by the outermost closed temperature anomaly contour. After all cold eddies are identified, they are tracked in each layer with an eddy-tracking algorithm (e.g., Chaigneau et al., 2008), which is adapted from Penven et al. (2005) and has been successfully used in studies on regional eddies (Penven et al., 2005; Chaigneau et al., 2008; Chen et al., 2011). Using this algorithm, the variation of the LCE and its track with depth and time can be identified. Fig. 5 shows the tracks of the eddy centers, which are detected from the SSHA at surface and from potential temperature 
anomalies at depths of $199 \mathrm{~m}$ and $875 \mathrm{~m}$, respectively. Study findings show that the cold eddy track at $199 \mathrm{~m}$ is basically similar to that detected from the SSHA at surface, and the traditionally known LCE is in fact a cold eddy existing in the upper $300 \mathrm{~m}$. It originates from northwest of the Luzon Island, moves northwestward, and finally decays in the northern SCS continental slope at about $115^{\circ} \mathrm{E}, 20^{\circ} \mathrm{N}$. Another cold eddy exists at a depth below $500 \mathrm{~m}$, and its track is quite different, e.g., the cold eddy track at $875 \mathrm{~m}$ suggests that this eddy originates from west of the southern Luzon Strait, moves westward with a slight southward migration, and finally decays near the Xisha Islands.

The three-dimensional structure of potential temperature anomalies, velocity anomalies and vorticities in December are shown in Fig.6. This reflects that the central position and radius of the LCE are significantly different between the upper (Fig.6a) and lower (Fig.6c) layers. The radius of the LCE in the upper layer increases with increasing depth, while it decreases in the lower layer. The central position of the LCE in the upper layer (Fig.6a) is near the Luzon Island, while that in the lower layer (Fig.6c) is situated farther west at about $115^{\circ}$ E near the western SCS continental slope. The velocity within the LCE in the lower layer exhibits a spiral pattern (Fig.6c) that is not apparent in the upper layer. The possible reason may be that the strong circulation current obscures the spiral pattern in the upper layer. The LCE central position mainly corresponds with the local vorticity extreme (Figs.6b, d). Notably, in the $18^{\circ} \mathrm{N}$ section, another local vorticity extreme (Fig.6b) is found to the west of the upper layer LCE centered at about $115^{\circ} \mathrm{E}, 18^{\circ} \mathrm{N}$, but there is only one vorticity extreme in the lower layer (Fig.6d). 
As depicted in Figs.7-8, if the LCE does not exist at a depth/time, the corresponding grid in the figures is grey-shaded; otherwise, the grid value represents the magnitude of the LCE characteristic parameter at that depth and time. Figs.7a, b show the longitudinal and latitudinal positions of the cold eddies' centers versus depth and time. In winter, the cold eddy can be identified down to depths more than 1,500 $\mathrm{m}$. In the upper layer at depths of 100-300 m, the upper layer cold eddy lasts from late November to late June. However, at depths below $500 \mathrm{~m}$, the lower layer cold eddy is generated in August through October and decays in April to May. The different eddies track at depths of $199 \mathrm{~m}$ and $875 \mathrm{~m}$ suggests that the cold eddies at these two depths may be affected by different dynamic processes. Herein, this study refers to the eddy at a depth above $300 \mathrm{~m}$ as the upper layer LCE and at a depth below $500 \mathrm{~m}$ as the lower layer LCE.

Study findings show that the cold eddy center varies with depth. From November to February, the center axis of the upper layer LCE tilts westward with increasing depth (Fig.7a), while after March the center axis is nearly vertical. The upper layer LCE moves mainly northwestward at a mean horizontal speed of $3.2 \pm 1.9 \mathrm{~cm} / \mathrm{s}$ (Figs.7c, d), while the lower layer LCE moves westward with a slight southward migration (Fig.7d) at a mean horizontal speed of $3.8 \pm 2.4 \mathrm{~cm} / \mathrm{s}$. The zonal speed of the upper layer LCE is relatively slow at the initial and end stages of its duration but fast at its middle stage with a speed of $4-8 \mathrm{~cm} / \mathrm{s}$, similar to the phase speed of the Rossby wave in this area (Cai et al., 2008). The speed of the lower layer LCE is slightly faster than that of the upper layer. 
Consistent with Chelton et al. (2011), the amplitude of the cold eddy is defined as the magnitude of the difference between the potential temperature anomalies in the eddy boundary and center. Fig.8a shows that the amplitude of the upper layer LCE is larger than that of the lower layer LCE. The time when the amplitude of the upper layer LCE reaches its maximum varies with depth, i.e., at a depth of $150 \mathrm{~m}$, the amplitude peaks with a value of $-0.47 \mathrm{~K}$ in April; at a depth of $250 \mathrm{~m}$, it peaks with a value of $-0.41 \mathrm{~K}$ in January. For the lower layer LCE, its amplitude reaches its maximum around December, i.e., at a depth of $720 \mathrm{~m}$, the amplitude peaks with a value of $-0.16 \mathrm{~K}$. In each layer, the variation of the cold eddy amplitude correlates with its radius (Fig.8b). The maximum radii of the upper and lower layers LCEs can reach more than $250 \mathrm{~km}$. For example, at a depth of $250 \mathrm{~m}$, the LCE radius peaks at $258 \mathrm{~km}$ in January and, at a depth of $720 \mathrm{~m}$, the radius peaked at $264 \mathrm{~km}$ in November.

The mean vertical velocities of the two cold eddies are both shown in Fig.8c. The maximum mean vertical velocity of the upper layer LCE is about $0.9 \mathrm{~m} /$ day at a depth of $118 \mathrm{~m}$ in December, while the minimum is about $-0.15 \mathrm{~m} /$ day at a depth of $199 \mathrm{~m}$ in April. Ekman pumping and divergence are two primary factors affecting the vertical velocity of the cold eddy. The mean vertical velocities of the upper and lower layers LCEs are upward before March, while it subsequently turns downward. This variation corresponds to the seasonal variation of the wind stress curl in the northern SCS, in which the positive wind stress curl anomaly in October through March leads to an upward vertical velocity and vice versa for the negative anomaly after April. The divergence induced by the upper layer LCE can strengthen the upward vertical velocity but weaken the downward velocity. However, usually this vertical velocity inversion has not been observed in the lower layer LCE. 
The vorticity intensity of the cold eddy, $\zeta$, is given by

$$
\varsigma=\frac{\iint\left(\frac{\partial v}{\partial x}-\frac{\partial u}{\partial y}\right) d S}{S}
$$

where $S$ is the area of eddy. In the upper layer, the vorticity intensity generally decreases with increasing depth (Fig. 8d), and it peaks in November to December, e.g., the maximum vorticity intensity of the upper layer LCE is $1.88 \times 10^{-6} \mathrm{~s}^{-1}$ at a depth of $118 \mathrm{~m}$ in December, implying that the wind forcing is an important factor affecting the vorticity intensity of upper layer LCE. However, in the lower layer the vorticity intensity peaks in January to February, e.g., the maximum vorticity intensity of the lower layer LCE is $1.29 \times 10^{-6} \mathrm{~s}^{-1}$ at a depth of $590 \mathrm{~m}$ in February. Considering that the lower layer LCE center is located at $113-114^{\circ} \mathrm{E}$ near the Xisha Islands in January to February (Fig.7a), the topographic effect may play an important role in the variation of the vorticity intensity of the lower layer LCE.

\subsection{Vorticity balance}

The vertical component of the vorticity equation under the Boussinesq approximation is defined as

$$
\begin{aligned}
& \frac{\partial \zeta}{\partial t}+\left(\vec{V}_{h} \cdot \nabla_{h}\right) \zeta+w \frac{\partial \zeta}{\partial z}+\beta v= \\
& \left(\vec{\omega}_{h} \cdot \nabla_{h}\right) w+(f+\zeta) \frac{\partial w}{\partial z}+A_{h}\left(\frac{\partial^{2} \zeta}{\partial x^{2}}+\frac{\partial^{2} \zeta}{\partial y^{2}}\right)+A_{z} \frac{\partial^{2} \zeta}{\partial z^{2}}
\end{aligned}
$$

where $\zeta$ is the vertical component of the vorticity, $\vec{\omega}_{h}$ is the horizontal component 
of the vorticity and $\nabla_{h}$ is the horizontal divergence operator. Taking a vertical intergral $\int_{h_{2}}^{h 1} d z$ to Eq.(2), and using the conservation equation, and the vorticity is non-divergent, we obtain

$$
\begin{aligned}
& \underbrace{\overline{\partial \zeta}}_{a}+\underbrace{\overline{\nabla_{h} \cdot V_{h} \zeta}}_{b}+\underbrace{\beta \bar{v}}_{c}= \\
& \underbrace{\overline{\nabla_{h} \cdot\left(w \vec{\omega}_{h}\right)}}_{d}+\underbrace{f w_{h 1}}_{e}-\underbrace{f w_{h 2}}_{f}+\underbrace{\left.A_{z} \frac{\partial \zeta}{\partial z}\right|_{z=h 1}}_{g}-\underbrace{\left.A_{z} \frac{\partial \zeta}{\partial z}\right|_{z=h 2}}_{h}+\underbrace{\overline{F_{h}}}_{i},
\end{aligned}
$$

where the $\bar{A}$ represents vertical integration, $\int_{h 2}^{h 1} A d z$. The left side of Eq. (3) includes (a) local derivative of relative vorticity, (b) advection of relative vorticity, and (c) beta term or advection of planetary vorticity. The sum of (b) and (c) is referred to as advection of potential vorticity. The right side of Eq. (3) includes (d) tilting term, planetary vorticity stretching term at (e) top interface and (f) bottom interface, vertical diffusion at (g) top interface and (h) bottom interface, and (i) horizontal diffusion term. When $h 1$ is at the sea surface, using sea surface dynamic boundary condition

$$
\left.A_{z} \frac{\partial \zeta}{\partial z}\right|_{z=\eta}=\frac{\operatorname{curl}(\vec{\tau})}{\rho_{0}}
$$

then term $(\mathrm{g})$ becomes vorticity input term of the wind stress curl.

Fig.9 shows the vorticity budget in the upper layer LCE. It should be noted that before January, the wind stress curl is the largest term in the vorticity equation. The other major terms are beta term, vorticity advection, planetary vorticity stretching at $282 \mathrm{~m}$ and local derivative of vorticity. Typically, these terms balance with the wind 
curl term, and the other terms in Eq. (3) are trivial except in May and June. The upper layer LCE is affected by positive wind stress curl before March and conversely negative after March, which corresponds with vertical velocity direction in the upper layer LCE (Fig. 7c). The local derivative of vorticity reaches its maximum in early December, corresponding with a rapid increase of the wind stress curl. The magnitude of relative vorticity advection is equivalent to planetary vorticity advection in late October. Subsequently, the planetary vorticity advection dominates the potential vorticity advection. The ratio of relative vorticity advection to planetary vorticity advection $(\zeta / f)$ is equal to the Rossby number ( $U / f L)$, so when the radius of the LCE $(L)$ increases, this ratio decreases. The planetary vorticity stretching at the bottom interface can transport vorticity downward. Study results show that this term is positive before February and then becomes negative.

The vorticity budget in the lower layer LCE is shown in Fig.10. Before October, the potential vorticity advection balances with the planetary vorticity stretching, and the other terms in vorticity equation are relatively small, which clearly reflects the Svedrup's relationship (Pedlosky, 1996). In October, the vorticity inputting from the upper layer (i.e., planetary vorticity stretching term at top interface, $530 \mathrm{~m}$ ) as well as the local derivative of vorticity increases. Meanwhile, the vorticity output from bottom interface also increases, transporting vorticity to deeper water. After February, vorticity inputting from the upper layer decreases and becomes negative in March. Conversely, the vertical velocity of the bottom interface $(1170 \mathrm{~m})$ increases. This phenomenon may be caused by the interaction of the lower layer LCE with the 
continental slope. These changes likely compress the planetary vorticity tube and generate a negative vorticity, which is balanced with the potential vorticity advection and friction.

\subsection{Sensitivity analysis}

Three sensitivity experiments, Exps.2, 3 and 4, are conducted to explore the effects of wind stress, wind stress curl and Kuroshio intrusion through the Luzon Strait, respectively, on the generation of the upper and lower layer LCE.

Fig. 11 shows the monthly potential temperature anomalies at a depth of $118 \mathrm{~m}$ in each experiment. In Exp.2 (Fig.11b), there is no cold eddy west of northern Luzon Island until April. This is the same in Exp.3 (Fig.11c) except that the cold eddy west of the northern Luzon Island with a larger potential temperature anomaly is generated earlier than that in Exp.2. From December to March, the results from Exp.4 (Fig.11d) are similar to those in Exp.1, except that the intensity and position of the upper layer LCE in Exp.4 are changed, and the upper layer LCE in Exp.4 almost disperses in May whilst that in Exp.1 remains until June.

Fig. 12 shows the monthly potential temperature anomalies at a depth of $875 \mathrm{~m}$ in each experiment. In Exp.2 (Fig.12b), positive and negative temperature anomalies, which correspond to negative and positive vorticities, respectively, are generated alternatively from the northeastern SCS and then propagate westward. The propagation speed is about $-2.6 \mathrm{~cm} / \mathrm{s}$ in $19^{\circ} \mathrm{N}$. A cyclonic eddy is generated west of the Luzon Strait in July and then moves westward. The result in Exp.3 (Fig.12c) is similar to that in Exp.2, except that the magnitude of potential temperature anomalies in 
Exp.3 is higher. However, in Exp.4 (Fig.12d), the lower layer LCE is generated in October, later than those in Exps.1-3; subsequently, it strengthens rapidly and moves westward with a track similar to Exp.1.

In summary, according to the results of the vorticity diagnostic analysis and comparison of the experimental results in Exps.1-3 (Figs.11a, b, c, respectively), the wind stress curl but not the uniform wind stress, is an essential factor affecting the generation of the upper layer LCE. Conversely, as shown in Exp.2, the Kuroshio intrusion seems to induce a warm eddy in the upper layer west of the northern Luzon Island from November to February but a cold eddy after March (Fig.11b). In the lower layer, a cold eddy moves westward from the Luzon Strait from June to September in Exps.1-3 (Figs. 12a, b, c, respectively), which is responsible for the generation of the lower layer LCE. Comparing the results in Exps.2-3 (Figs. 12b, c, respectively), the lower layer LCE is only slightly intensified by the uniform wind stress in the SCS, but it is significantly intensified by the wind stress curl after October.

\subsection{Eddy energy}

The eddy kinetic energy (EKE) and eddy available potential energy (EPE) of the cold eddies in Exp.1 and Exp.4 are calculated to estimate the contributions of wind stress curl and Kuroshio intrusion to the eddies, respectively. The EKE is given by 


$$
E K E=\frac{1}{2} \iint_{S}\left(u^{\prime 2}+v^{\prime 2}\right) d S
$$

where $u^{\prime}, v^{\prime}$ are the zonal and meridional velocity anomalies, and $\mathrm{S}$ is the area inside the eddy.

The EPE is calculated according to a definition based on the quasi-geostrophic approximation (Pedlosky, 1987; Oort et al., 1989, 1994):

$$
E P E=-\frac{1}{2 \bar{\rho}} \iint_{S} g(\rho-\bar{\rho})^{2}\left(\frac{\partial \widetilde{\rho}}{\partial z}\right)^{-1} d S
$$

where $\bar{\rho}$ is the yearly-mean potential density in the SCS and $\widetilde{\rho}$ is the horizontal average over the yearly-mean potential density in the SCS. Considering that the density variation in the ocean is mainly due to the variation of the temperature, the density of water approximately depends on potential temperature $\theta$ in a linear function,

$$
\rho=\bar{\rho}(1-\alpha(\theta-\bar{\theta}))
$$

where $\alpha$ is the expansion coefficient of water at $\theta=\bar{\theta}$, and $\bar{\theta}$ is the time-mean potential temperature. Hence, the PE in term of temperature is,

$$
P E=\frac{1}{2} \alpha g \iint_{S} \frac{(\theta-\bar{\theta})^{2}}{\partial \widetilde{\theta} / \partial z} d S
$$

EKE and EPE of the LCE at a depth of $118 \mathrm{~m}$ and $875 \mathrm{~m}$ are illustrated to represent the temporal variations of the upper layer and the lower layer LCE, respectively.

Fig.13 shows that the EPEs of upper and lower layer LCE (Figs.13c, d) are roughly 10 times larger than the EKEs (Figs.13a, b), respectively. This is because the 
horizontal scale of motion is larger than the radius of deformation, thus the EPE is larger than EKE. In Exp.1, the EKE of the upper layer LCE reaches local extrema in early January and early April with values of $3.5 \times 10^{7} \mathrm{~m}^{2} / \mathrm{s}^{2}$ and $2.7 \times 10^{7} \mathrm{~m}^{2} / \mathrm{s}^{2}$, respectively, while the EPE reaches an annual maximum of $3.3 \times 10^{8} \mathrm{~m}^{2} / \mathrm{s}^{2}$ in early April. However, in Exp.4, both the EKE and EPE of upper layer LCE reach an annual maximum in January. The EKE and EPE of the upper layer LCE in Exp.4 from January to February is significantly larger than that in Exp.1. This demonstrates that the Kuroshio intrusion weakens the upper layer LCE before March, contradictory to previous study findings that the Kuroshio intrusion induces a positive vorticity to strengthen the LCE (Yang and Liu, 2003). This conclusion is also observed in Exp.2 (see Fig.9b), in which an anti-cyclonic eddy induced by the Kuroshio intrusion dominates the northwest of the Luzon Island from November to February. In Exp.1, the EPE and EKE of the lower layer LCE reach an annual maximum in December. The annual maximum values of EPE and EKE in Exp. 1 are $3.0 \times 10^{6} \mathrm{~m}^{2} / \mathrm{s}^{2}$ and $1.2 \times 10^{8}$ $\mathrm{m}^{2} / \mathrm{s}^{2}$, respectively. In November, the EPE and EKE in Exp.4 are about half of those in Exp.1. This suggests that the Kuroshio intrusion plays an important role in enhancing the lower layer LCE.

Why does the Kuroshio intrusion reduce the energy of the upper layer LCE but increase the energy of the lower layer LCE? In this study, the LCE energy is equal to the product of the LCE radius and the energy intensity. In the upper layer, from December to March the LCE radius (Fig.14a) in Exp.1 is significantly smaller than that in Exp.4, while the EKE intensity (Fig.14c) and EPE intensity (similar as EKE intensity, not shown) of the LCE in Exp.1 are larger than those in Exp.4. However, in the lower layer from October to January, the LCE radius and EKE intensity (Fig.14b) in Exp.1 are slightly larger than those in Exp.4. When compared with Fig.11, it is 
suggested that the energy difference between the LCEs in Exp.1 and Exp.4 is mainly due to the difference in the LCE radius, while the energy intensity is of minor effect.

How does the Kuroshio intrusion influence the LCE radius and energy intensity? To address this question, this work illustrates the velocity anomaly, which is equal to the velocity in Exp.1 minus that in Exp.4 and its corresponding vorticity in Fig.15. At $118 \mathrm{~m}$ in January (Fig.15a), there is an anti-cyclonic anomaly centered at around $\left(117.5^{\circ} \mathrm{E}, 17.5^{\circ} \mathrm{N}\right)$ and a cyclonic anomaly centered at around $\left(119.5^{\circ} \mathrm{E}, 18.5^{\circ} \mathrm{N}\right)$. Those anomalies, which seem to be an effect of the Kuroshio intrusion, make the LCE in Exp. 1 center at around the cyclonic anomaly and enhance the vorticity intensity in the LCE. The center of the LCE in Exp.1, located northeast of that in Exp.4, is close to the Luzon Island, so its radius is limited by the coast of Luzon. At $875 \mathrm{~m}$ in November (Fig.15b), there are two cyclonic anomalies centered west of the Luzon Strait (around $\left.119^{\circ} \mathrm{E}, 21^{\circ} \mathrm{N}\right)$ and at around $\left(117^{\circ} \mathrm{E}, 18^{\circ} \mathrm{N}\right)$, respectively. This result indicates that the Kuroshio intrusion increases the lower layer LCE radius and energy intensity.

\section{Conclusions}

A variable-grid global ocean circulation model $(\mathrm{MITgcm})$ was validated and employed to study the LCEs in the northern SCS. This study provided a detailed description of the three-dimensional structure and spatiotemporal variability of the LCEs. The effects of wind stress, wind stress curl and the Kuroshio intrusion on the LCEs were also discussed.

First, the potential temperature anomalies were used to identify and track the cold eddy in each layer. In winter, the cold eddy could be well identified down to a 
depth below $1500 \mathrm{~m}$ and, in fact, it was found that there were two cold eddies northwest of the Luzon Island. In the upper layer, the track of the LCE detected from the potential temperature anomaly was similar to that detected from the SSHA. The cold eddy above $300 \mathrm{~m}$ (below $500 \mathrm{~m}$ ) depth was referred to as the upper (lower) layer LCE because of different generation sites, properties and dynamic mechanisms of the eddies in the upper and lower layers.

In this study, the upper layer LCE lasted from late November to late June. It was generated northwest of the Luzon Island, moved northwestward at a mean horizontal speed of $3.2 \pm 1.9 \mathrm{~cm} / \mathrm{s}$ and finally decayed at about $\left(115.5^{\circ} \mathrm{E}, 20^{\circ} \mathrm{N}\right)$. From November to February, the central axis of upper layer LCE tilted westward with increasing depth, while after March, the center axis was nearly vertical. This was when the amplitude of the upper layer LCE reached its maximum variation with depth. The mean vertical velocity of the upper layer LCE was upward before March and then subsequently turned downward. The vorticity intensity peaked in December to January, generally decreasing with increasing depth.

The lower layer LCE originated from west of the southern Luzon Strait in August through October, moved westward with a little southward migration at a mean horizontal speed of $3.8 \pm 2.4 \mathrm{~cm} / \mathrm{s}$ and finally decayed near the Xisha Islands in April to May. Its amplitude and radius reached a maximum around December. The mean vertical velocity of lower layer LCE was mainly upward. The vorticity intensity of lower layer LCE peaked in January to February. In both the upper and lower layers, the variation of the cold eddy amplitude closely correlated with that of its radius.

The generating mechanisms were different between the upper and lower layer LCEs. The upper layer LCE was mainly induced by the winter wind stress curl in the 
SCS, but it was weakened by the Kuroshio intrusion until March. The lower layer LCE originated from a cold eddy, which moved westward from the Luzon Strait and then was intensified by the wind stress curl after October. This suggested that the Kuroshio intrusion played an important role in enhancing the lower layer LCE. Notably without the Kuroshio intrusion, the EKE and EPE of the lower layer LCE could be reduced by as much as half.

The upper layer LCE has been well documented in previous literature (e.g. $Q u$, 2000; Yang and Liu, 2003), but there are few relevant reports on the lower layer LCE. Fig.16 depicts the potential temperature anomaly from WOA2009 monthly climatology at a depth of $900 \mathrm{~m}$. This depicts that a cold anomaly was located east of the Xisha Islands (about $113^{\circ} \mathrm{E}, 18^{\circ} \mathrm{N}$ ) in February, corresponding to the lower layer LCE near the Xisha Islands in Exp.1 (Fig.12b). In October, a sandwiched horizontal structure with a warm-cold-warm anomaly spread from the eastern Xisha Islands to the Luzon Island, corresponding to Exp.1 in October (Fig.12b). According to this study, the lower layer LCE might have been responsible for the seasonal variability of the potential temperature in the deep water east of the Xisha Islands. Limited by the spatial resolution of the WOA2009 data, it is hard to distinguish the eddy structure. Therefore, more detailed observations are needed for studying eddies at greater depths.

Overall, most studies of the eddy census and statistics have been based on sea surface data (e.g., Chelton et al., 2011; Chen et al., 2011; Yang et al., 2013), while studies of eddies at greater depths are limited. This study suggests that at greater depths, the eddy location and distribution may be largely different than that in the upper layer. Nonetheless, this model study is only preliminary, and more observational data are 
needed to verify these conclusions to better understand the eddy and circulation in deep water.

Acknowledgements: We thank Professor R. Huang for enlightening suggestions and three anonymous referees for helpful comments. This work was jointly supported by the Special Fund of Strategic Leading Science and Technology from Chinese Academy of Sciences under Contract No. XDA11020201, National Basic Research Program (No. 2013CB956101), NSFC Grants 41206009, 41430964 and 41025019, and the CAS/SAFEA International Partnership Program for Creative Research Teams. The altimeter products were produced by Ssalto/Duacs and distributed by AVISO, with support from Cnes (http://www.aviso.oceanobs.com/duacs/). QuikScat data were produced by Remote Sensing Systems and sponsored by the NASA Ocean Vector Winds Science Team. Data are available at www.remss.com. NCEP/DOE 2 reanalysis data were provided by the NOAA/OAR/ESRL PSD, Boulder, Colorado, USA, via http://www.esrl.noaa.gov/psd/. We gratefully acknowledge the use of the HPCC at South China Sea Institute of Oceanology, Chinese Academy of Sciences for all numerical simulations.

\section{References:}

Boyer, T., C. Stephens, J. Antonov, M. Conkright, R. Locarnini, T. O'Brien, and H. Garcia (2002), World Ocean Atlas 2001. Volume 2, Salinity. 
Cai, S. Q., X. M. Long, R. H. Wu, and S. G. Wang (2008), Geographical and monthly variability of the first baroclinic Rossby radius of deformation in the South China Sea, Journal of Marine Systems, 74(1-2), 711-720.

Chaigneau, A., A. Gizolme, and C. Grados (2008), Mesoscale eddies off Peru in altimeter records: Identification algorithms and eddy spatio-temporal patterns, Progress In Oceanography, 79(2-4), 106-119.

Chelton, D. B., M. G. Schlax, and R. M. Samelson (2011), Global observations of nonlinear mesoscale eddies, Progress In Oceanography, 91(2), 167-216.

Chen, G., Y. Hou, and X. Chu (2011), Mesoscale eddies in the South China Sea: Mean properties, spatiotemporal variability, and impact on thermohaline structure, Journal of Geophysical Research: Oceans , 116(C6), C06018.

Dong, C., X. Lin, Y. Liu, F. Nencioli, Y. Chao, Y. Guan, D. Chen, T. Dickey, and J. C. McWilliams (2012), Three-dimensional oceanic eddy analysis in the Southern California Bight from a numerical product, Journal of Geophysical Research: Oceans , 117(C7), C00H14.

Hu, J., J. Gan, Z. Sun, J. Zhu, and M. Dai (2011), Observed three-dimensional structure of a cold eddy in the southwestern South China Sea, Journal of Geophysical Research: Oceans, 116(C5), C05016.

Large, W. G., J. C. McWilliams, and S. C. Doney (1994), Oceanic vertical mixing: A review and a model with a nonlocal boundary layer parameterization, Reviews of 
Geophysics, 32(4), 363-403.

Leith, C. E. (1996), Large eddy simulation of complex engineering and geophysical flows, Physica D, 98, 481-491.

Liu, Y., R. H. Weisberg, and Y. Yuan (2008), Patterns of upper layer circulation variability in the South China Sea from satellite altimetry using the self-organizing map, Acta Oceanologica sinica, 27(z1).

Liu, X. B., and J. L. Su (1992), A reduced gravity model of the circulation in the South China Sea, Oceanologia et Limnologia Sinica, 23, 167- 174, (in Chinese).

Marshall, J., C. Hill, L. Perelman, and A. Adcroft (1997), Hydrostatic, quasi-hydrostatic, and nonhydrostatic ocean modeling, Journal of Geophysical Research: Oceans, 102(C3), 5733-5752.

Metzger, E. (2003), Upper Ocean Sensitivity to Wind Forcing in the South China Sea, Journal of Oceanography, 59(6), 783-798.

Nan, F., Z. He, H. Zhou, and D. Wang (2011), Three long-lived anticyclonic eddies in the northern South China Sea, Journal of Geophysical Research: Oceans, 116(C5), C05002.

Oort, A. H., S. C. Ascher, S. Levitus, and J. P. Peixóto (1989), New estimates of the available potential energy in the world ocean, Journal of Geophysical Research: Oceans, 94(C3), 3187-3200. 
Oort, A. H., L. A. Anderson, and J. P. Peixoto (1994), Estimates of the energy cycle of the oceans, Journal of Geophysical Research: Oceans, 99(C4), 7665-7688.

Pedlosky, J. (1987), Geophysical Fluid Dynamics, Springer, New York, 710 pp.

Pedlosky, J. (1996), Ocean Circulation Theory, Springer, New York, 8 pp.

Penven, P., V. Echevin, J. Pasapera, F. Colas, and J. Tam (2005), Average circulation, seasonal cycle, and mesoscale dynamics of the Peru Current System: A modeling approach, Journal of Geophysical Research: Oceans, 110(C10), C10021.

Qu, T. (2000), Upper-Layer Circulation in the South China Sea, Journal of Physical Oceanography, 30(6), 1450-1460.

Qu, T., H. Mitsudera, and T. Yamagata (2000), Intrusion of the North Pacific waters into the South China Sea, Journal of Geophysical Research: Oceans, 105(C3), $6415-6424$.

Shaw, P., S. Chao, K. Liu, S. Pai, and C. Liu (1996), Winter upwelling off Luzon in the northeastern South China Sea, Journal of Geophysical Research: Oceans, 101(C7), 16435-16448.

Stephens, C., J. Antonov, T. Boyer, M. Conkright, R. Locarnini, T. O'Brien, and H. Garcia (2002), World Ocean Atlas 2001. Volume 1, Temperature.

Sun, C. X., and Q. Y. Liu (2011), Double eddy structure of the winter Luzon Cold Eddy based on satellite altimeter data. Journal of Tropical Oceanography, 30(3), 
9-15.

Wang, G., J. L. Su, and Peter C. Chu (2003), Mesoscale eddies in the South China Sea observed with altimeter data, Geophysical Research Letters, 30(21), 2121.

Wang, G., D. Chen, and J. Su (2008), Winter Eddy Genesis in the Eastern South China Sea due to Orographic Wind Jets, Journal of Physical Oceanography, 38(3), 726-732.

Wyrtki, K. (1961), Physical oceanography of the Southeast Asian waters, Scientific results of marine investigations of the South China Sea and the gulf of Thailand 1959-1961, NAGA report, 2, 1-195.

Xiu, P., F. Chai, L. Shi, H. Xue, and Y. Chao (2010), A census of eddy activities in the South China Sea during 1993-2007, Journal of Geophysical Research: Ocean, 115(C3), C03012.

Xu, X., Z. Qiu, and H. Chen (1982), The general descriptions of the horizontal circulation in the South China Sea, in Proceedings of the 1980 Symposium of the Chinese Society of Marine Hydrology and Meteorology, pp. 119-127, Sci. Press, Beijing.

Yang, G., F. Wang, Y. Li, and P. Lin (2013), Mesoscale eddies in the northwestern subtropical Pacific Ocean: Statistical characteristics and three-dimensional structures, Journal of Geophysical Research: Oceans, 118, 1906-1925. 
Yang, H., and Q. Liu (2003), Forced Rossby wave in the northern South China Sea, Deep Sea Research Part I: Oceanographic Research Papers, 50(7), 917-926. 


\section{Figure caption:}

Fig. 1 (a) Model domain and grids, (b) bottom topography in the South China Sea (SCS) and West Pacific (WP), (c) domain (denoted by shaded areas) where the zero wind stress and zero wind stress curl are applied in Exp.2 and Exp.3, respectively, and blocked Luzon strait (denoted by thick solid lines) in Exp.4. Hatched area denotes box for calculating spatially averaged SSHA in Section 3.

Fig. 2 Sea Surface Heights in March, June, September and December from the satellite altimetry and the model result in Exp.1 (where the contour interval is $5 \mathrm{~cm})$.

Fig. 3 Vertical profile of monthly potential temperature anomaly in March, June, September and December (unit: $\mathrm{K}, \mathrm{CI}=0.2 \mathrm{~K}$ ) at $18^{\circ} \mathrm{N}$ from (a) WOA2009, (b) Exp.1. Note that the vertical scale of depth below $-300 \mathrm{~m}$ is three times larger than that above $-300 \mathrm{~m}$.

Fig. 4 Modelled monthly SSHA (thin contours, unit: $\mathrm{cm}$ ) in the SCS (where thick line denotes the boundary of the LCE) and AVISO monthly climatological SLA (colored shading, unit: $\mathrm{cm}$ ).

Fig. 5 Tracks of the cold eddies center in Exp.1 (where pentagrams denote the LCE centers identified from modelled SSHA from November to July, dots denote the cold eddy centers at a depth of $119 \mathrm{~m}$ from November to July, open circles denote those at a depth of $875 \mathrm{~m}$ from August to May, and arrows denote the direction of eddy movement. The interval of each symbol is 15 days) 
Fig. 6 (a) Three-dimensional structures of potential temperature anomalies (unit: K, color shading) and velocity (vectors) in upper layer. (b) Three-dimensional structures of vorticity (unit: $\mathrm{s}^{-1}$, color shading) in upper layer. (c) Some as (a) but for lower layer. (d) Some as (c) but for lower layer. Thick black line denotes the boundary of the LCE at each depth.

Fig. 7 (a) Variation of the longitudinal position (unit: ${ }^{\circ} \mathrm{E}$, color shaded) of the upper and lower layers LCEs centers versus depth and time in Exp.1, (b) same as (a) but for latitudinal position (unit: ${ }^{\circ} \mathrm{N}$ ), and (c) same as (a) but for propagating velocity in zonal (unit: $\mathrm{cm} / \mathrm{s}$ ). (d) Same as (a) but for propagating velocity in meridional (unit: $\mathrm{cm} / \mathrm{s}$ ). Grid with grey shading represents that LCE cannot be identified at this depth in this time.

Fig. 8 Some properties of the upper and lower layers LCEs. (a) Amplitude (unit: K), (b) radius (unit: $\mathrm{km}$ ), (c) mean vertical velocity (unit: m/day), and (d) vorticity intensity (unit: $10^{-6} \mathrm{~s}^{-1}$ ).

Fig.9 Vorticity budget of the upper layer LCE in Exp.1. The wind stress curl term (black solid line with dots), planetary vorticity stretching term at a depth of $282 \mathrm{~m}$ (blue dashed line with upward pointing triangles), beta term (red solid line with downward-pointing triangles), vorticity advection (black dashed line with stars) and vorticity local derivative (red dashed line with squares) are first vertically integrated from sea surface to $282 \mathrm{~m}$ and then horizontally averaged within a LCE domain. Here the LCE domain is identified by modelled SSHA (Fig.3). Green dashed line with crosses denotes the sum of the above 5 terms except wind curl term. The wind stress curl term is calculated from the QuikSCAT monthly 
climatological wind.

Fig.10 Same as Fig.1 but for the lower layer LCE. Values are first vertically integrated from $530 \mathrm{~m}$ to $1170 \mathrm{~m}$ and then horizontally averaged within a LCE domain. Here the LCE domain is identified at a depth of $875 \mathrm{~m}$.

Fig. 11 Monthly potential temperature anomaly (unit: K) at $118 \mathrm{~m}$ in (a) Exp.1 $(\mathrm{CI}=0.2 \mathrm{~K}),(\mathrm{b}) \operatorname{Exp} .2(\mathrm{CI}=0.1 \mathrm{~K}),(\mathrm{c}) \operatorname{Exp} .3(\mathrm{CI}=0.2 \mathrm{~K})$, and (d) Exp.4 $(\mathrm{CI}=0.2 \mathrm{~K})$.

Fig. 12 Monthly potential temperature anomaly (unit: K) at $875 \mathrm{~m}$ in (a) Exp.1 $(\mathrm{CI}=0.02 \mathrm{~K})$, (b) Exp.2 (CI=0.005K), (c) Exp.3 (CI=0.02K), and (d) Exp.4 $(\mathrm{CI}=0.02 \mathrm{~K})$.

Fig. 13 (a) EKE (unit: $\mathrm{m}^{2 /} \mathrm{s}^{2}$ ) of the LCE at a depth of $118 \mathrm{~m}$. (b) Same as (a) but at a depth of $875 \mathrm{~m}$. (c) EPE (unit: $\mathrm{m}^{2 /} \mathrm{s}^{2}$ ) of the LCE at a depth of $118 \mathrm{~m}$. (d) Same as (c) but at a depth of $875 \mathrm{~m}$. Solid/dashed line with circle/triangles denotes energy in Exp.1/Exp.4.

Fig.14 Time series of (a) LCE Radius at 118m depth, (b) LCE Radius at 875m depth, (c) LCE EKE intensity at $118 \mathrm{~m}$ depth, and (d) LCE EKE intensity at $875 \mathrm{~m}$ depth in Exp.1 and Exp.4.

Fig.15 Velocity (arrow) and vorticity (color shaded) difference between Exp.1 and Exp.4 at (a) $118 \mathrm{~m}$ in Januray; (b) $875 \mathrm{~m}$ in November. Black solid (dashed) line denotes the edge of the LCE in Exp.1 (Exp.4). Black dot (triangle) denotes the LCE center in Exp.1 (Exp.4). 
Fig. 16 WOA2009 potential temperature anomaly (unit: K) at 900m in (a) February $(\mathrm{CI}=0.05 \mathrm{~K}),(\mathrm{b})$ October $(\mathrm{CI}=0.02 \mathrm{~K})$. 
Table 1 Vertical spacing of the numerical model

\begin{tabular}{|c|c|c|c|}
\hline Layer & Thickness (m) & $\begin{array}{c}\text { Depth of Intermediate } \\
\text { Level (m) }\end{array}$ & $\begin{array}{c}\text { Depth of Lower } \\
\text { Interface (m) }\end{array}$ \\
\hline 1 & 10 & 5 & 10 \\
\hline 2 & 12 & 16 & 22 \\
\hline 3 & 15 & 29.5 & 37 \\
\hline 4 & 18 & 46 & 55 \\
\hline 5 & 22 & 66 & 77 \\
\hline 6 & 25 & 89.5 & 102 \\
\hline 7 & 32 & 118 & 134 \\
\hline 8 & 40 & 154 & 174 \\
\hline 9 & 50 & 199 & 224 \\
\hline 10 & 58 & 253 & 282 \\
\hline 11 & 68 & 316 & 350 \\
\hline 12 & 80 & 390 & 430 \\
\hline 13 & 100 & 480 & 530 \\
\hline 14 & 120 & 590 & 650 \\
\hline 15 & 140 & 720 & 790 \\
\hline 16 & 170 & 875 & 960 \\
\hline 17 & 210 & 1065 & 1170 \\
\hline 18 & 260 & 1300 & 1430 \\
\hline 19 & 300 & 1580 & 1730 \\
\hline 20 & 380 & 1920 & 2110 \\
\hline 21 & 450 & 2335 & 2560 \\
\hline 22 & 560 & 2840 & 3120 \\
\hline 23 & 680 & 3460 & 3800 \\
\hline 24 & 800 & 4200 & 4600 \\
\hline 25 & 1000 & 5100 & 5600 \\
\hline
\end{tabular}


Table 2 Scheme of four experiments

\begin{tabular}{ll}
\hline Experiments & Scheme \\
\hline Exp.1 (control) & $\begin{array}{l}\text { It is driven by QuikSCAT monthly climatology with all } \\
\text { straits in the SCS opened }\end{array}$ \\
Exp.2 (no wind) & No wind forcing in the SCS \\
Exp.3 (no wind stress curl) & Uniform wind stress in the SCS \\
Exp.4 (no Kuroshio intrusion) & Luzon Strait is closed \\
\hline
\end{tabular}

Two cold eddies at different depths northwest of Luzon Islands are indentified

Lower layer LCE originates from a cold eddy west of the Luzon Strait

Contributions of wind and Kuroshio intrusion to lower layer LCE are about equal 


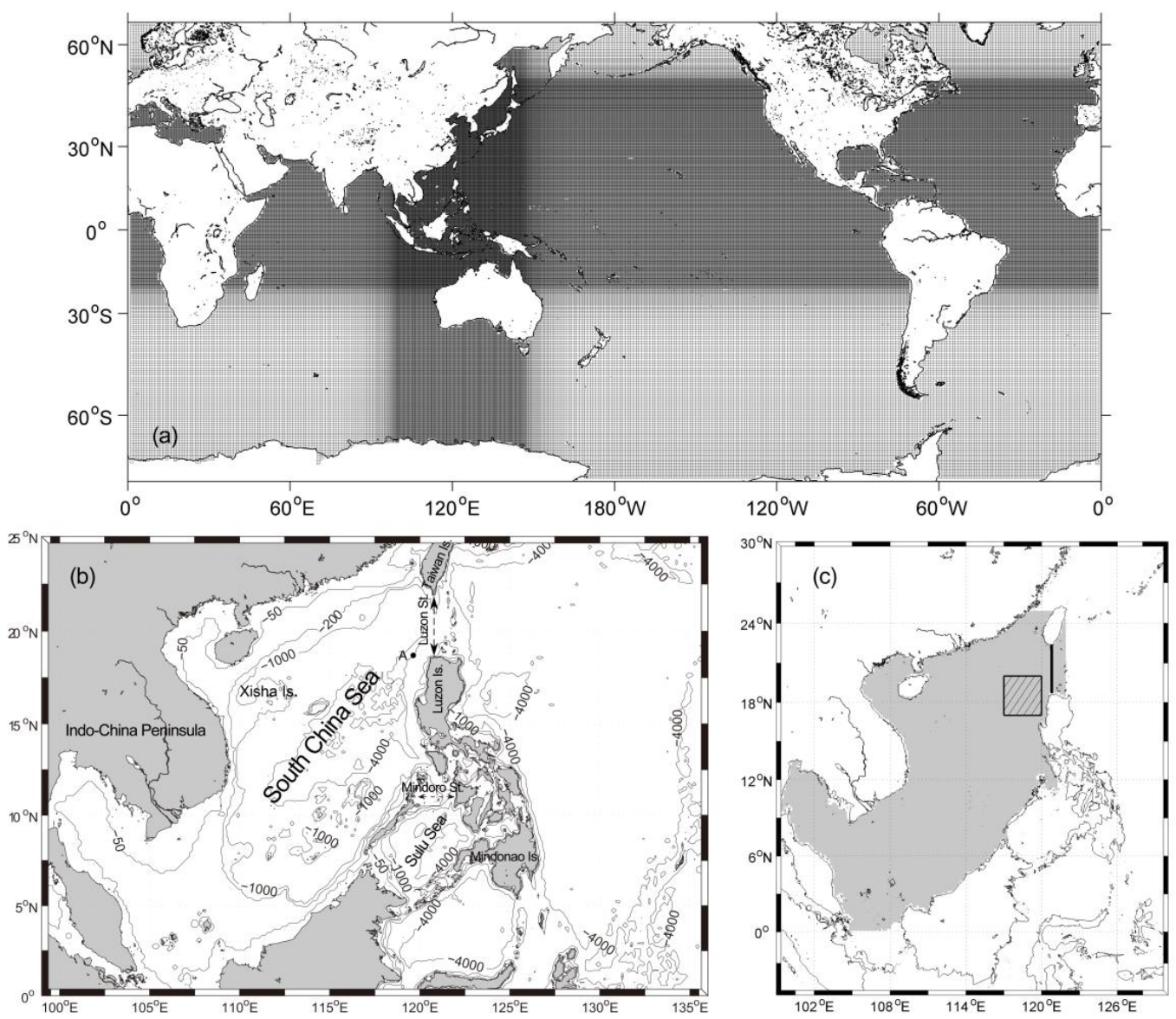

Fig. 1 (a) Model domain and grids, (b) bottom topography in the South China Sea (SCS) and West Pacific (WP), (c) domain (denoted by shaded areas) where the zero wind stress and zero wind stress curl are applied in Exp.2 and Exp.3, respectively, and blocked Luzon strait (denoted by thick solid lines) in Exp.4. Hatched area denotes box for calculating spatially averaged SSHA in Section 3 . 
(a) AVISO
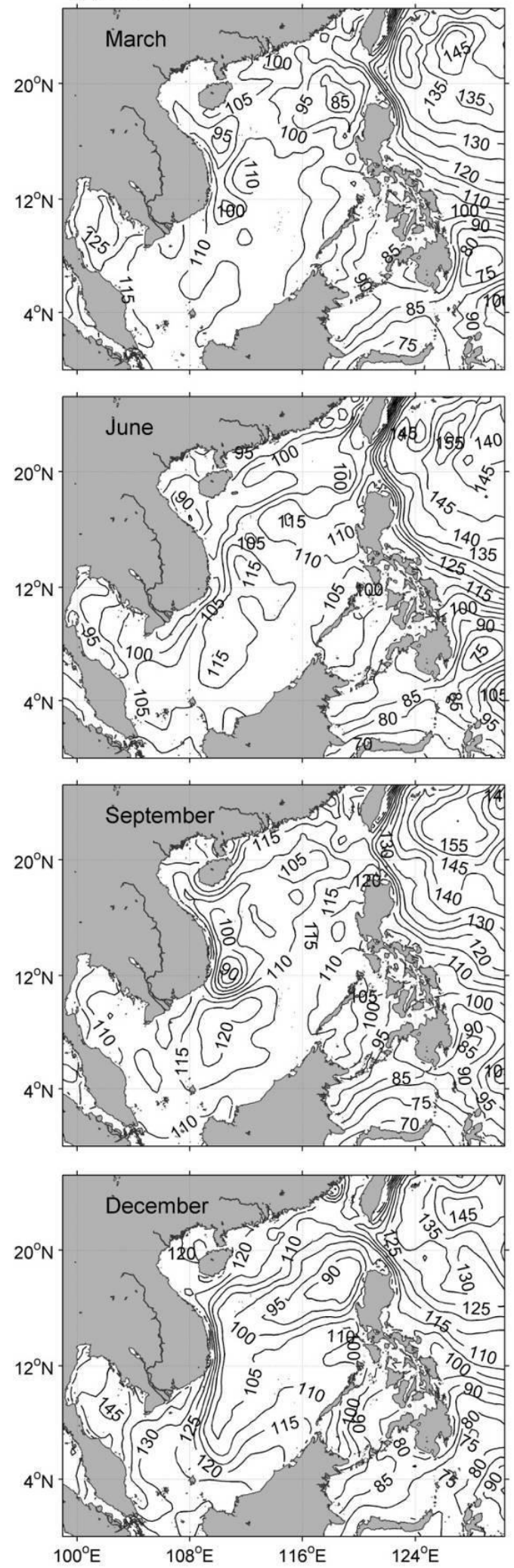

(b) Model
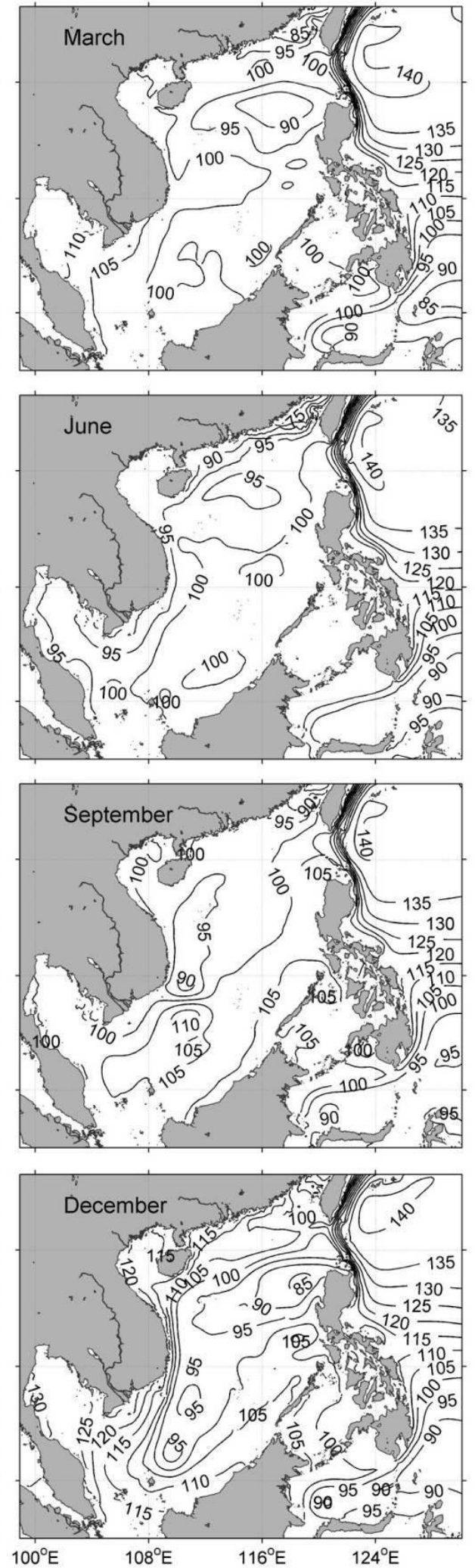

Fig. 2 Sea Surface Heights in March, June, September and December from the satellite altimetry and the model result in Exp.1 (where the contour interval is $5 \mathrm{~cm}$ ). 
(a) WOA2009

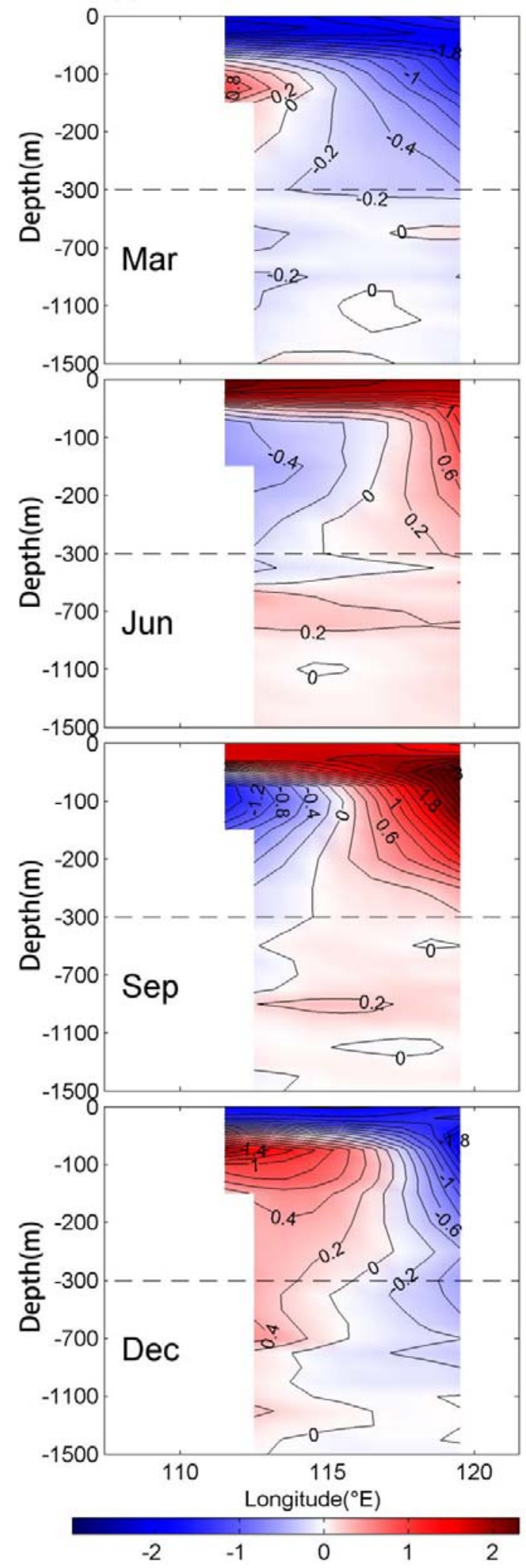

(b) Exp.1
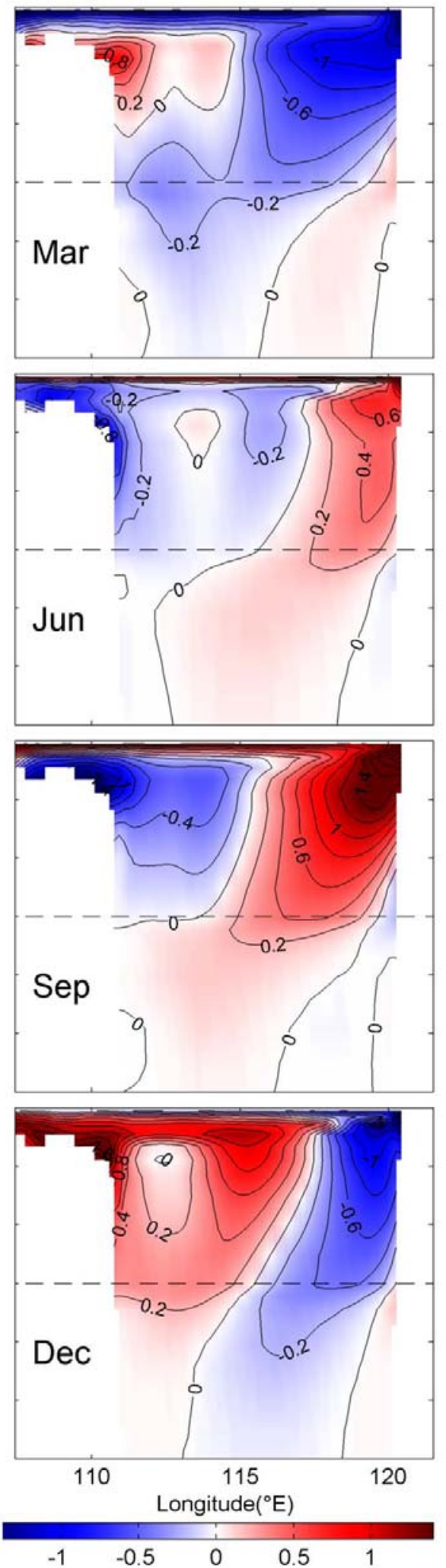

Fig. 3 Vertical profile of monthly potential temperature anomaly in March, June, September and December (unit: $\mathrm{K}, \mathrm{CI}=0.2 \mathrm{~K}$ ) at $18^{\circ} \mathrm{N}$ from (a) WOA2009, (b) Exp.1. Note that the vertical scale of depth below $-300 \mathrm{~m}$ is three times larger than that above $-300 \mathrm{~m}$. 

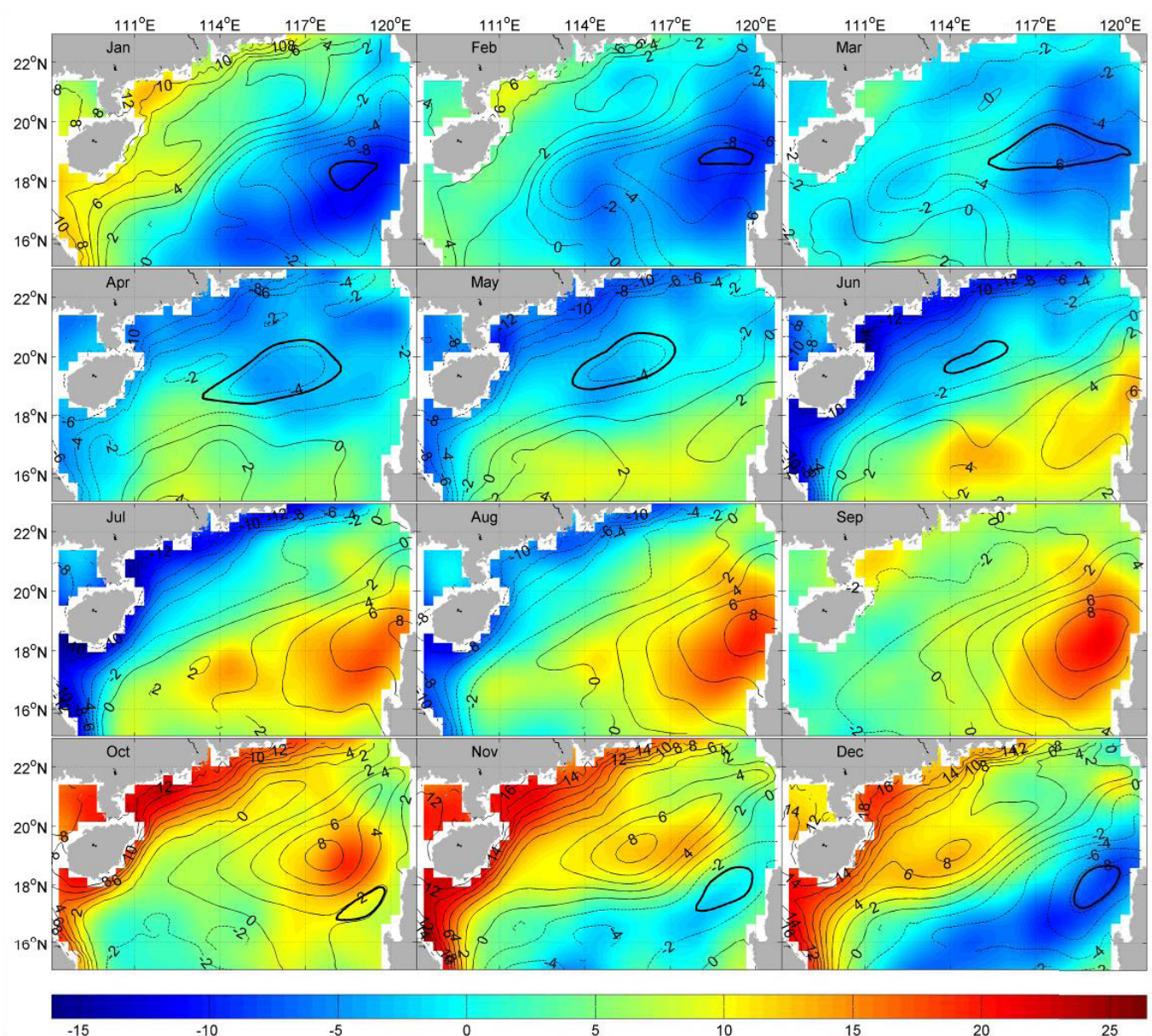

Fig. 4 Modelled monthly SSHA (thin contours, unit: $\mathrm{cm}$ ) in the SCS (where thick line denotes the boundary of the LCE) and AVISO monthly climatological SLA (colored shading, unit: $\mathrm{cm}$ ). 


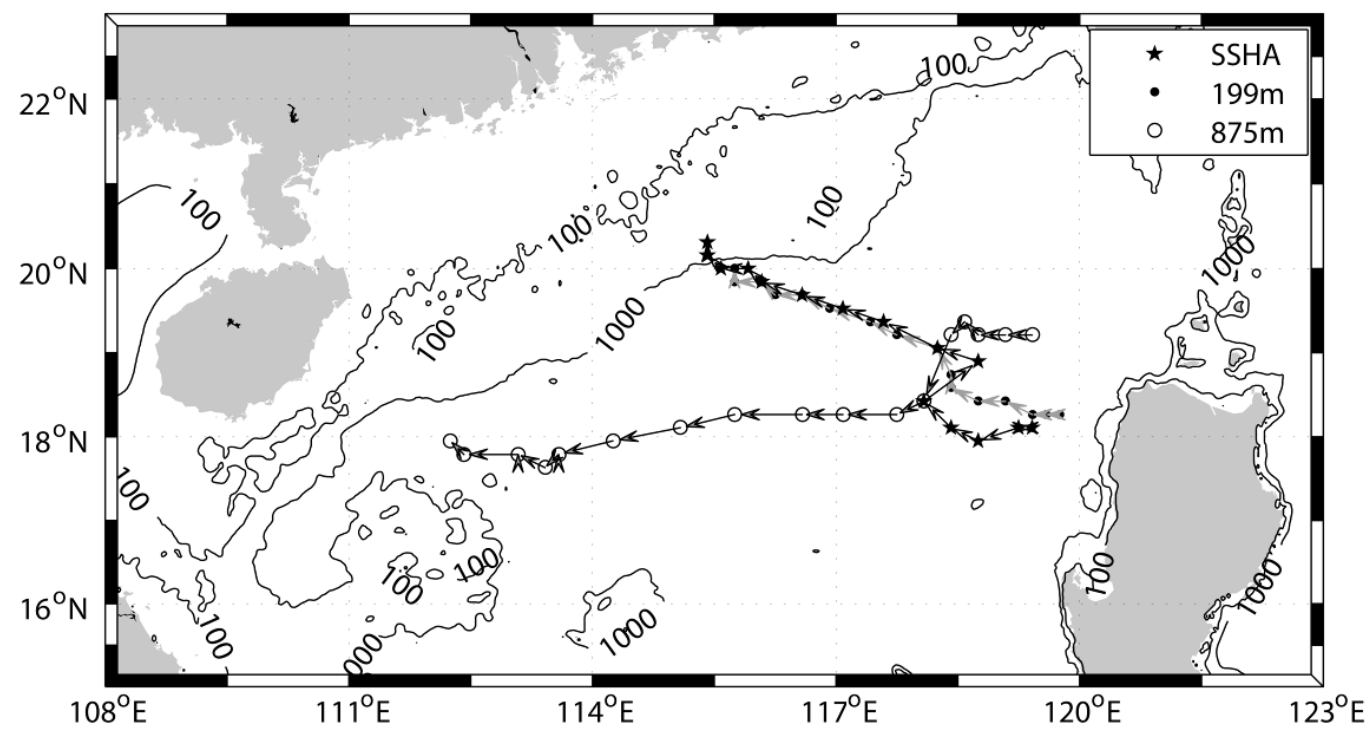

Fig. 5 Tracks of the cold eddies centers in Exp.1 (where pentagrams denote the LCE centers indentified from modelled SSHA from November to July, dots denote the cold eddy centers at a depth of $119 \mathrm{~m}$ from November to July, open circles denote those at a depth of $875 \mathrm{~m}$ from August to May, and arrows denote the direction of eddy movement. The interval of each symbol is 15 days) 

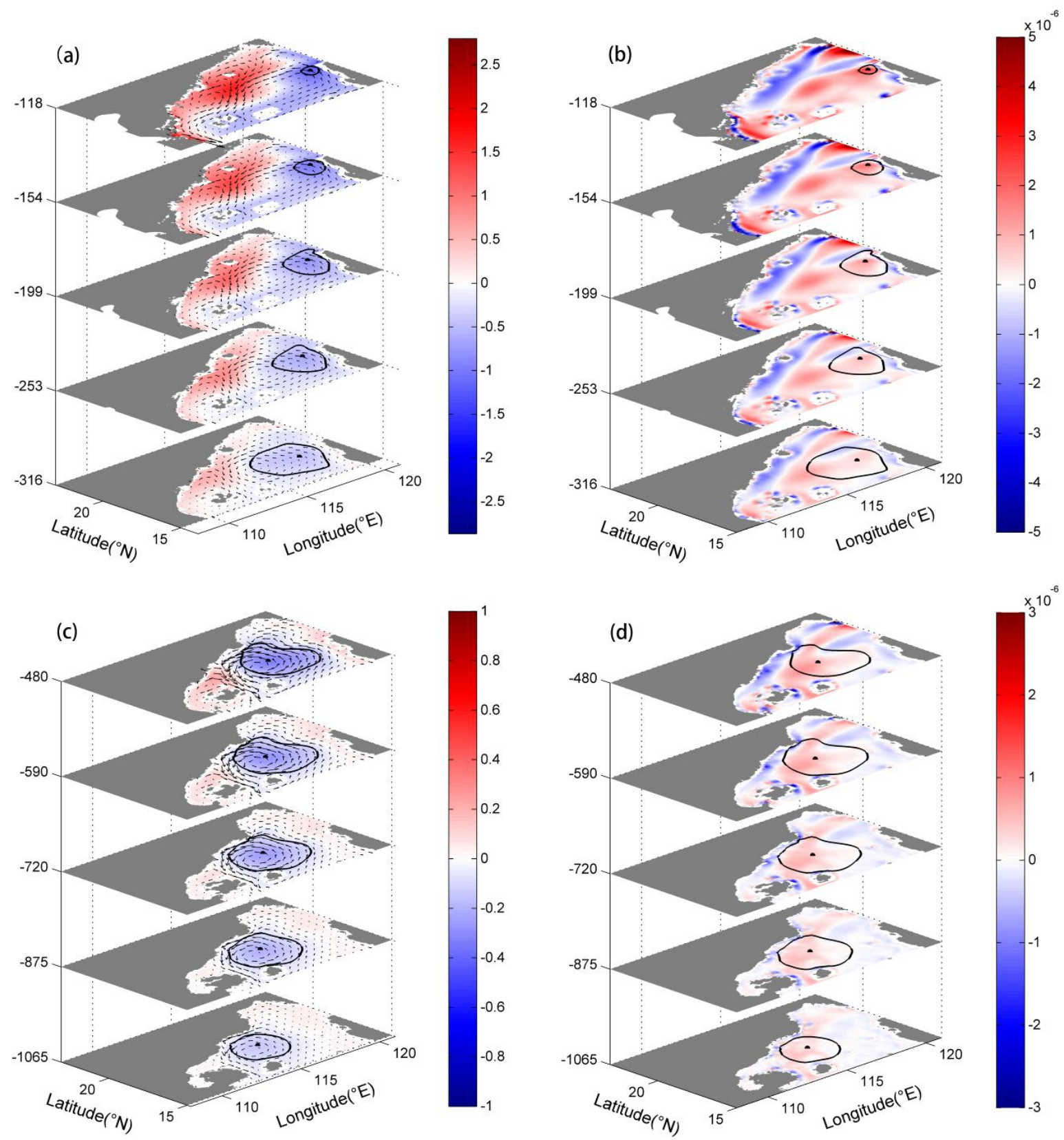

Fig. 6 (a) Three-dimensional structures of potential temperature anomalies (unit: K, color shading) and velocity (vectors) in upper layer. (b) Three-dimensional structures of vorticity (unit: $\mathrm{s}^{-1}$, color shading) in upper layer. (c) Some as (a) but for lower layer. (d) Some as (c) but for lower layer. Thick black line denotes the boundary of the LCE at each depth. 
(a) Longitude $\left({ }^{\circ} \mathrm{E}\right)$

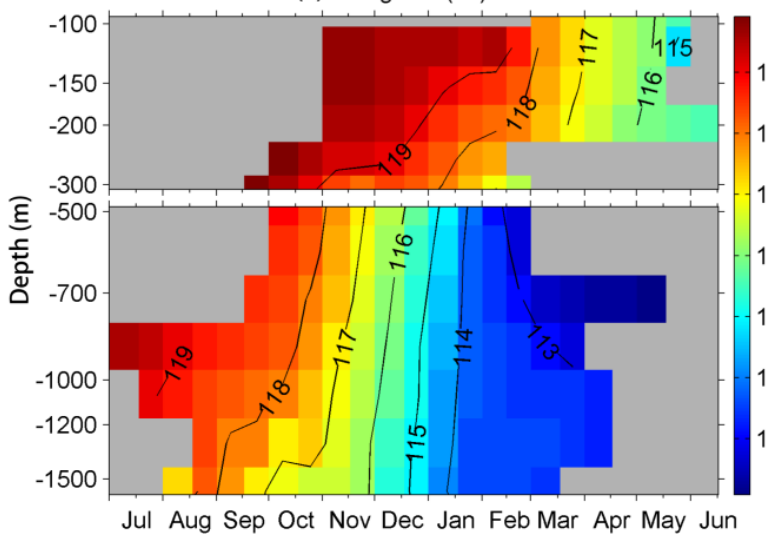

(c) Zonal Velocity $(\mathrm{cm} / \mathrm{s})$

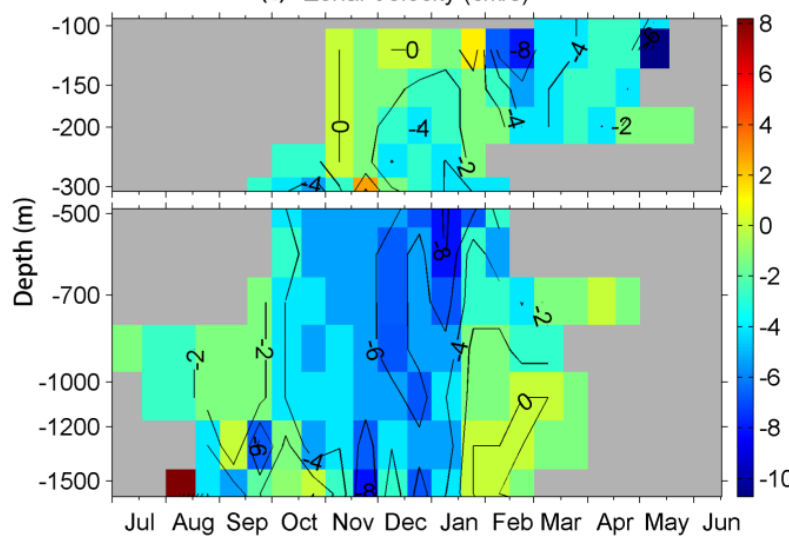

(b) Latitude $\left({ }^{\circ} \mathrm{N}\right)$

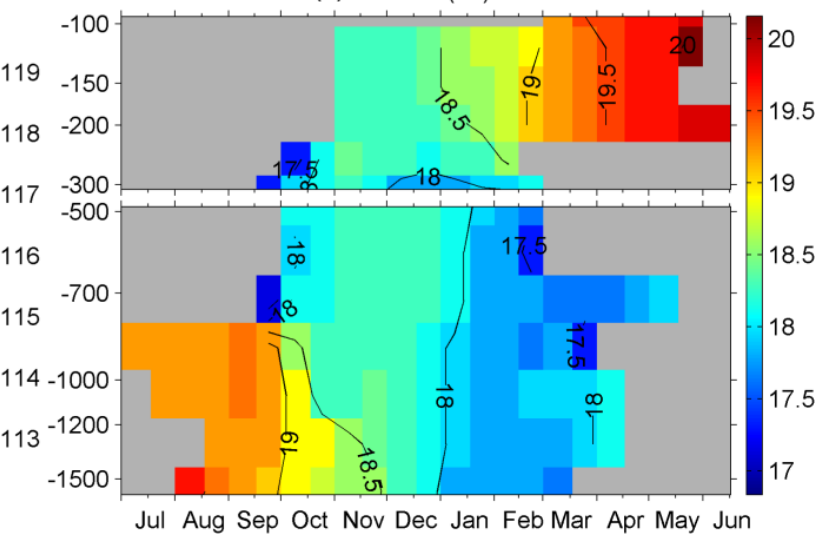

(d) Meridional Velocity $(\mathrm{cm} / \mathrm{s})$

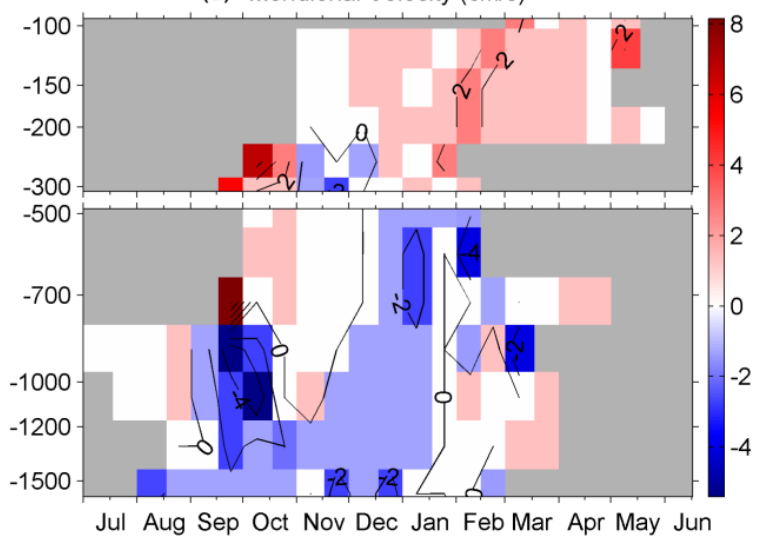

Fig. 7 (a) Variation of the longitudinal position (unit: ${ }^{\circ} \mathrm{E}$, color shaded) of the upper and lower layers LCEs centers versus depth and time in Exp.1, (b) same as (a) but for latitudinal position (unit: ${ }^{\circ} \mathrm{N}$ ), and (c) same as (a) but for propagating velocity in zonal (unit: $\mathrm{cm} / \mathrm{s}$ ). (d) Same as (a) but for propagating velocity in meridional (unit: $\mathrm{cm} / \mathrm{s}$ ). Grid with grey shading represents that LCE cannot be identified at this depth in this time. 
(a) Amplitude (K)

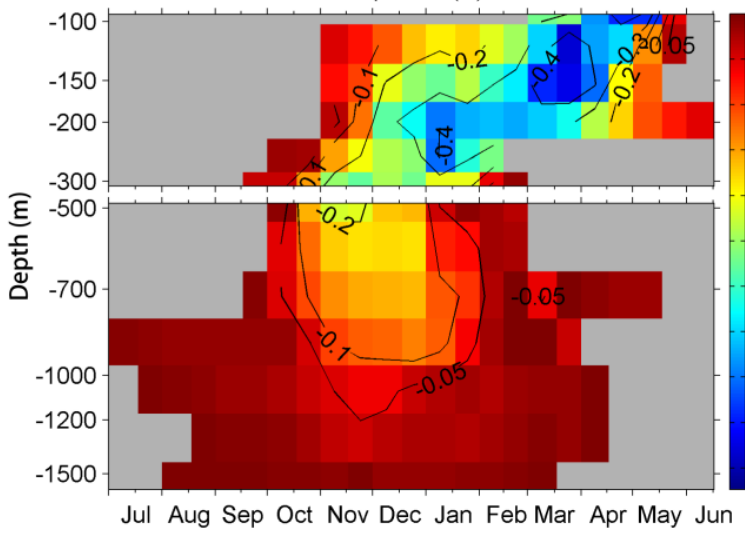

(c) Vertical Velocity (m/day)

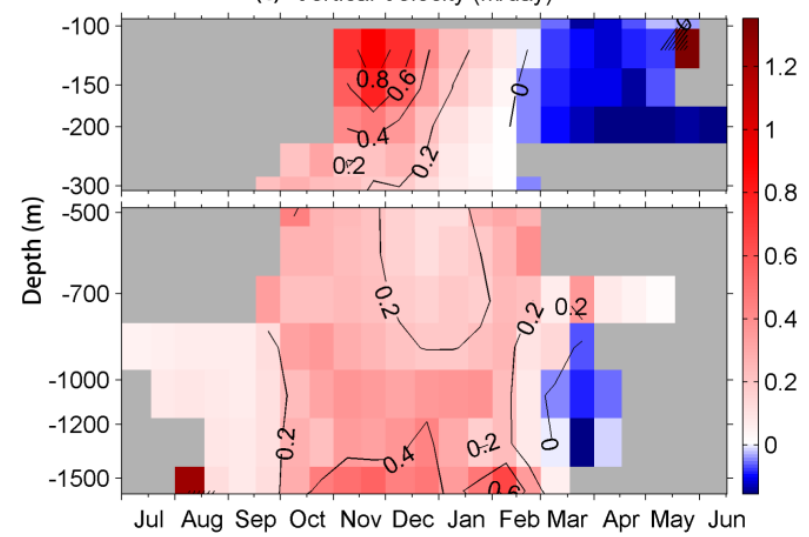

(b) Radius (km)

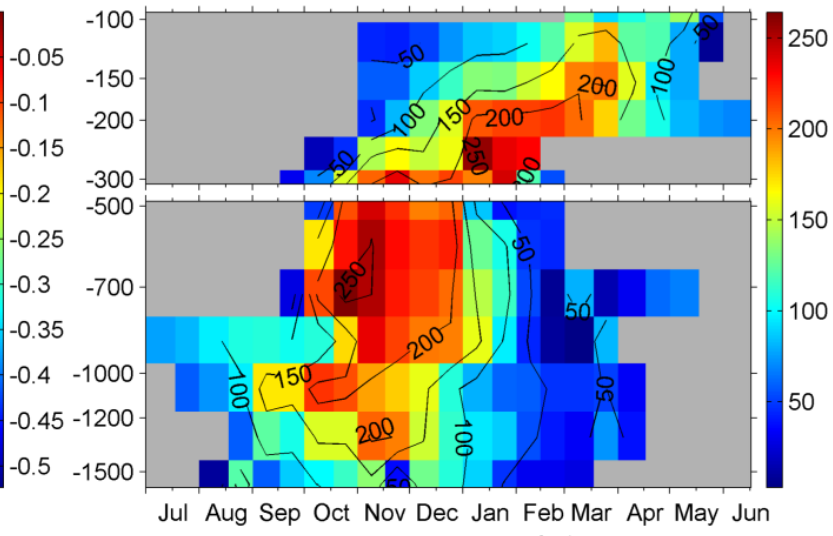

(d) Vorticity Intensity $\left(10^{-6} \mathrm{~s}^{-1}\right)$

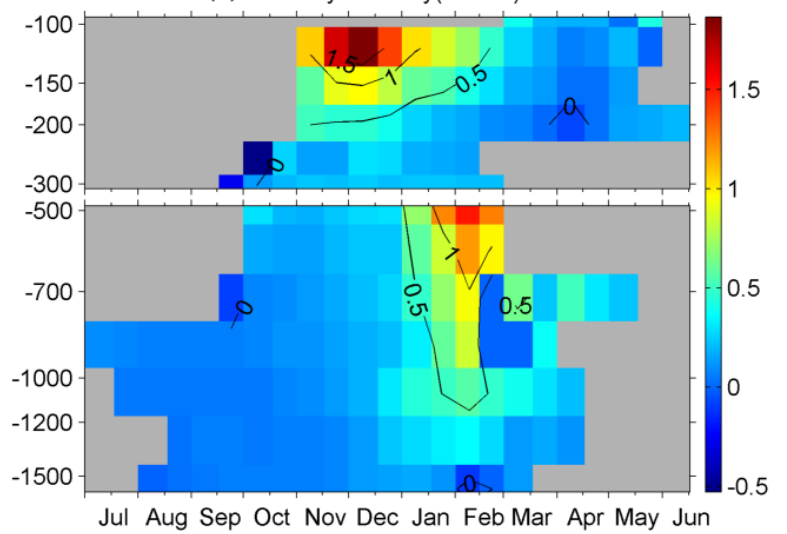

Fig. 8 Some properties of the upper and lower layers LCEs. (a) Amplitude (unit: K), (b) radius (unit: $\mathrm{km}$ ), (c) mean vertical velocity (unit: $\mathrm{m} /$ day), and (d) vorticity intensity (unit: $10^{-6} \mathrm{~s}^{-1}$ ). 


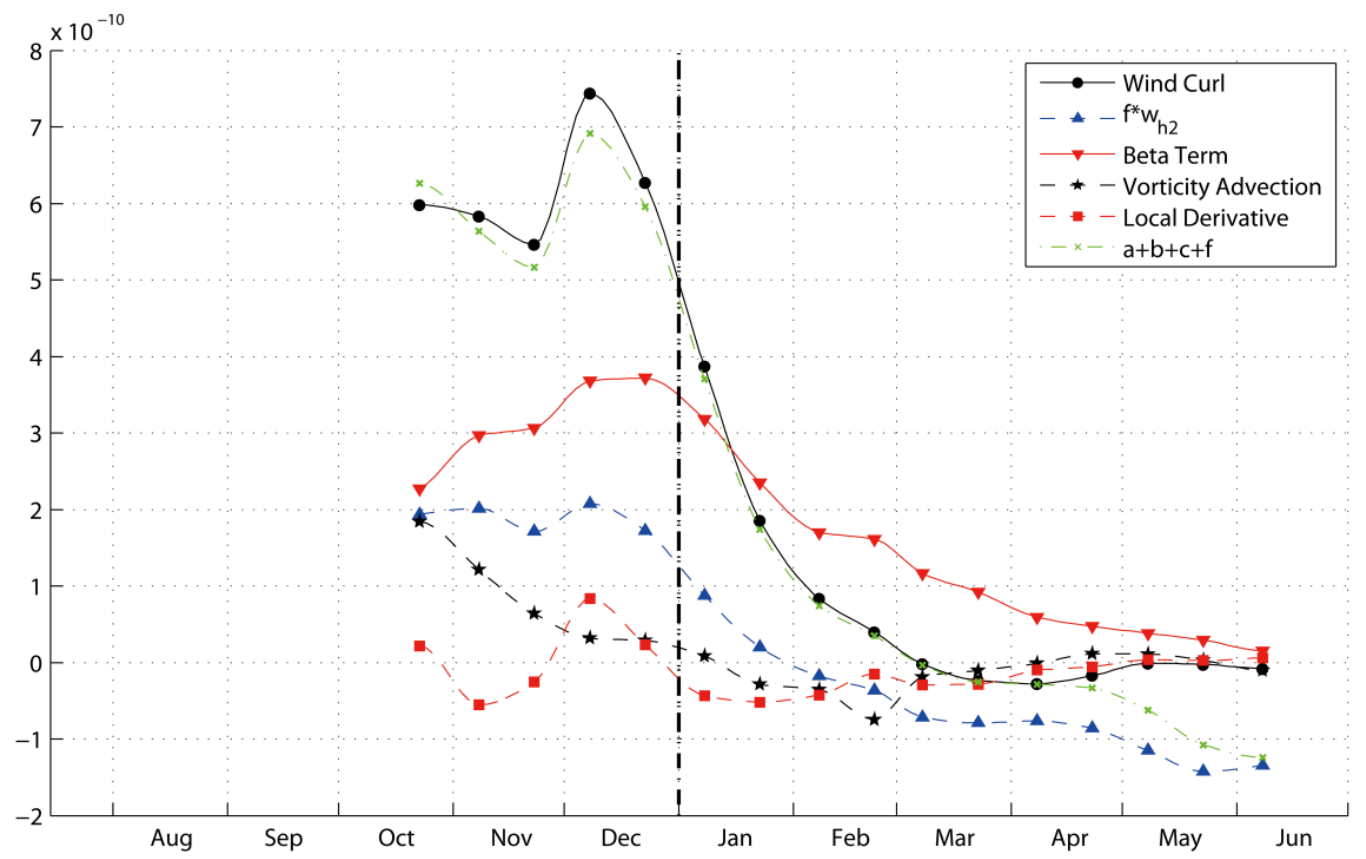

Fig.9 Vorticity budget of the upper layer LCE in Exp.1. The wind stress curl term (black solid line with dots), planetary vorticity stretching term at a depth of $282 \mathrm{~m}$ (blue dashed line with upward pointing triangles), beta term (red solid line with downward-pointing triangles), vorticity advection (black dashed line with stars) and vorticity local derivative (red dashed line with squares) are first vertically integrated from sea surface to $282 \mathrm{~m}$ and then horizontally averaged within a LCE domain. Here the LCE domain is identified by modelled SSHA (Fig.3). Green dashed line with crosses denotes the sum of the above 5 terms except wind curl term. The wind stress curl term is calculated from the QuikSCAT monthly climatological wind. 


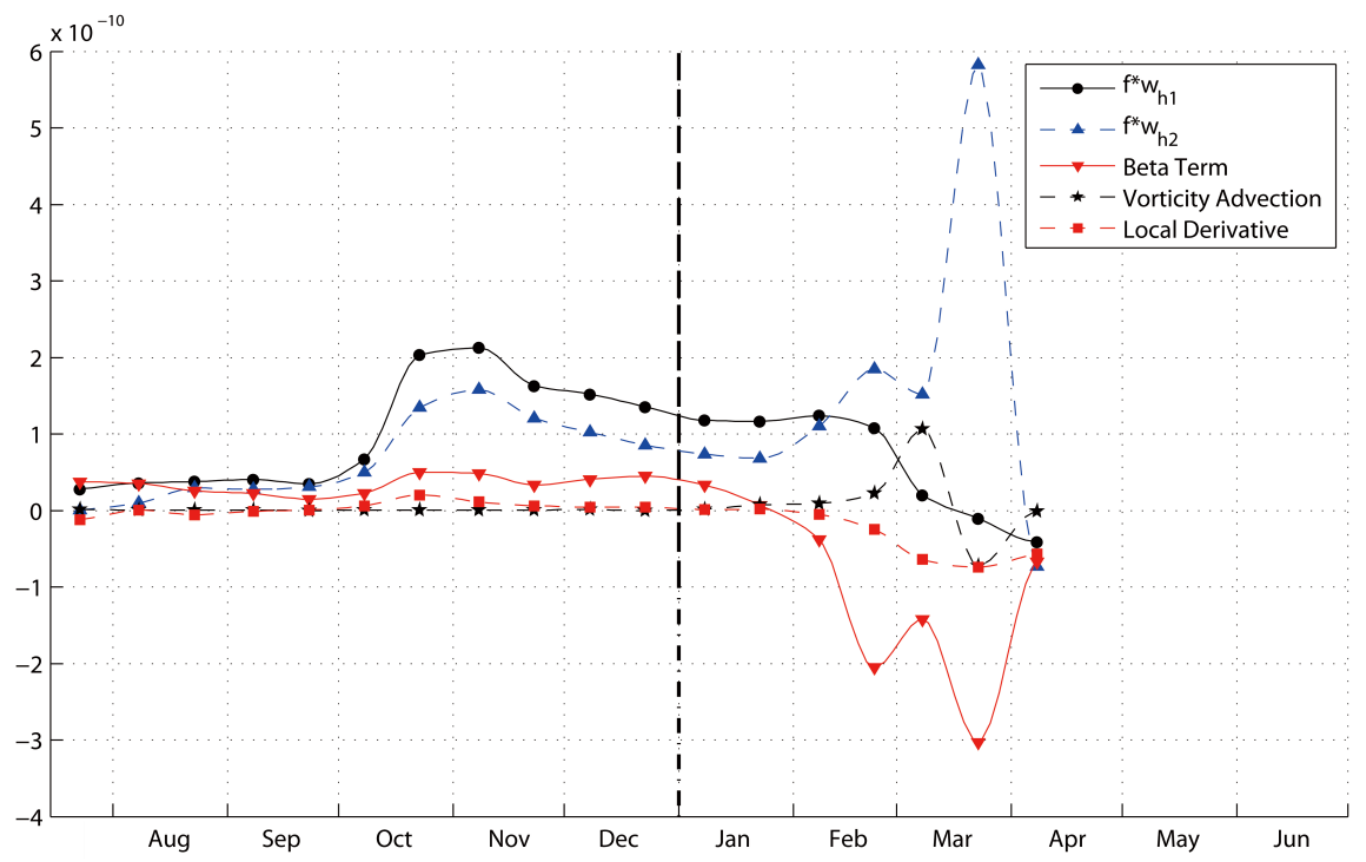

Fig.10 Same as Fig.1 but for the lower layer LCE. Values are first vertically integrated from 530m to $1170 \mathrm{~m}$ and then horizontally averaged within a LCE domain. Here the LCE domain is identified at a depth of $875 \mathrm{~m}$. 
(a) Exp.1

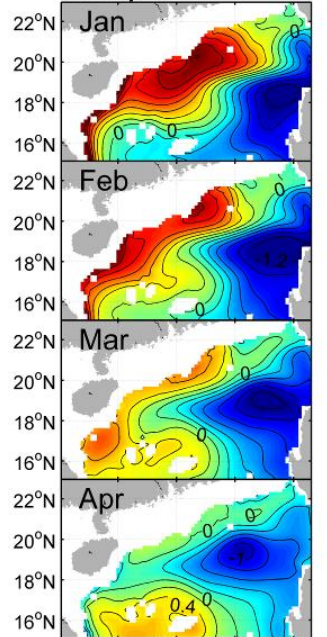

$22^{\circ} \mathrm{N}$ May

$20^{\circ} \mathrm{N}$

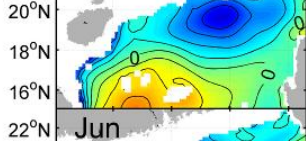

$22^{\circ} \mathrm{N}$ Jun

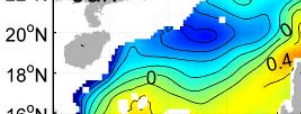

$16^{\circ} \mathrm{N}$

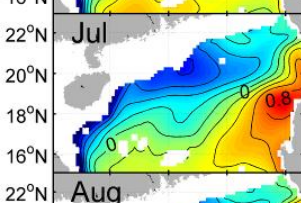

$22^{\circ} \mathrm{N}$ Aug

$20^{\circ} \mathrm{N}$.

$18^{\circ} \mathrm{N}$

$16^{\circ} \mathrm{N}$

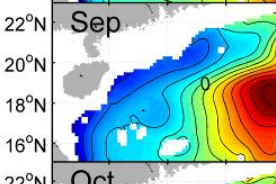

$22^{\circ} \mathrm{N}$ Oc

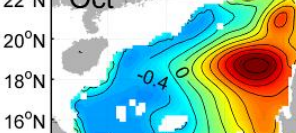

$16^{\circ} \mathrm{N}$

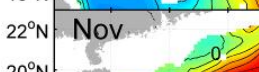

${ }_{20}^{\circ} \mathrm{N} \quad-03$

${ }_{18^{\circ} \mathrm{N}}^{2{ }^{\circ} \mathrm{N}}$

$16^{\circ} \mathrm{N}$

$22^{\circ} \mathrm{N}$ Dec -2

$20^{\circ} \mathrm{N}$

$18^{\circ} \mathrm{N}$
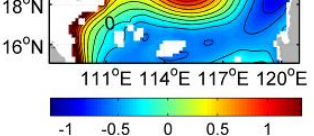

(b) Exp.2
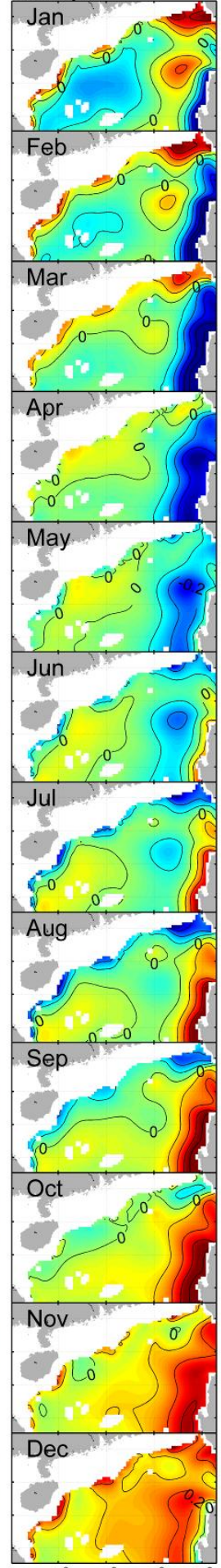

$111^{\circ} \mathrm{E} 114^{\circ} \mathrm{E} 117^{\circ} \mathrm{E} 120^{\circ} \mathrm{E}$

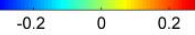

(c) Exp.3
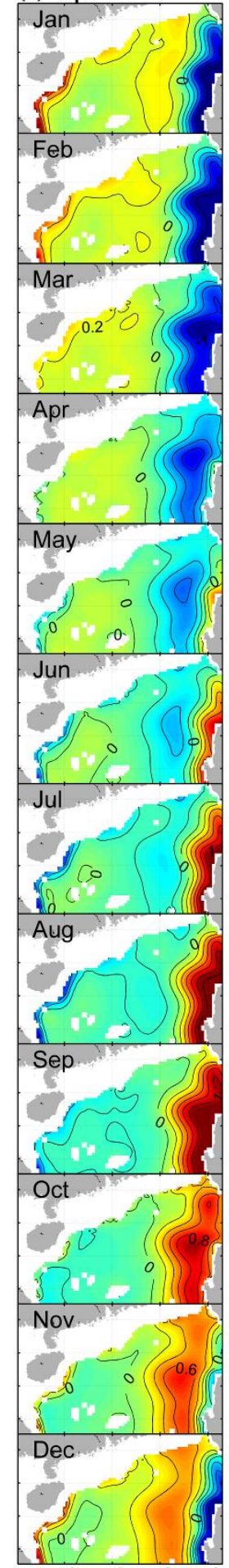

$111^{\circ} \mathrm{E} 114^{\circ} \mathrm{E} 117^{\circ} \mathrm{E} 120^{\circ} \mathrm{E}$

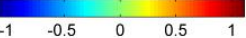

(d) Exp.4

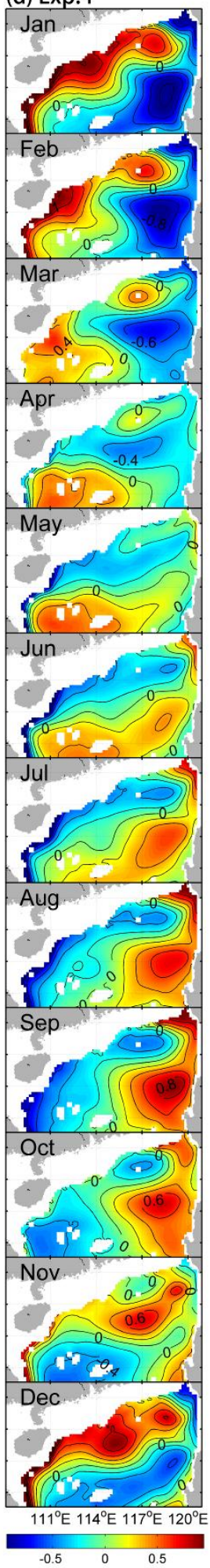

Fig. 11 Monthly potential temperature anomaly (unit: $\mathrm{K}$ ) at $118 \mathrm{~m}$ in (a) Exp.1 (CI=0.2K), (b) Exp.2 (CI=0.1K), (c) Exp.3 (CI=0.2K), and (d) Exp.4 (CI=0.2K). 
(a) Exp.1
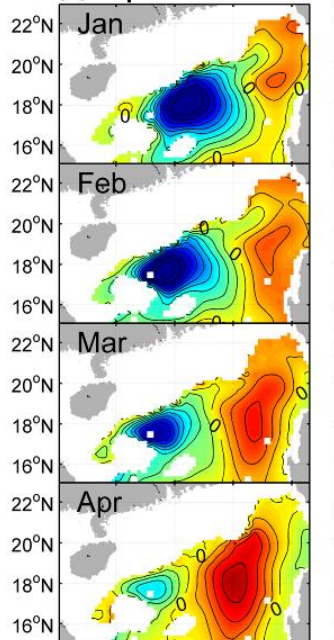

$22^{\circ} \mathrm{N}$ May

$20^{\circ} \mathrm{N}$

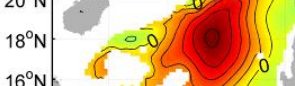

${ }_{22^{\circ} \mathrm{N} \text { Jun }} \mathrm{N}$

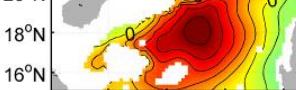

$22^{\circ} \mathrm{N}$ Jul

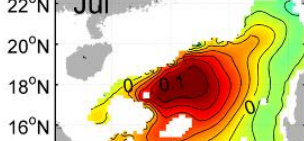

$22^{\circ} \mathrm{N}$ Aug

$20^{\circ} \mathrm{N}$

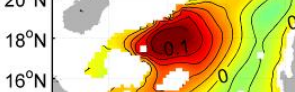

$22^{\circ} \mathrm{N}$ Sep
$20^{\circ} \mathrm{N}$
$18^{\circ} \mathrm{N}$
$16^{\circ} \mathrm{N}$

$22^{\circ} \mathrm{N}$ Oct

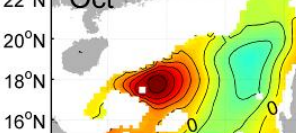

$22^{\circ} \mathrm{N}$ Nov
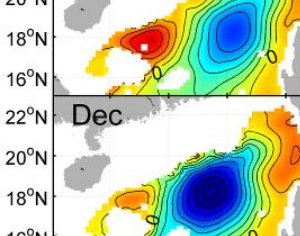

$16^{\circ} \mathrm{N}$

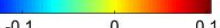

$20^{\circ} \mathrm{N}$

(b) Exp.2
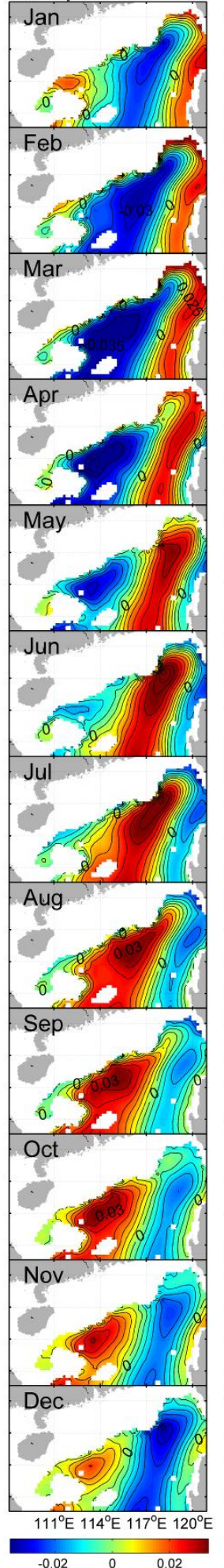

(c) Exp.3
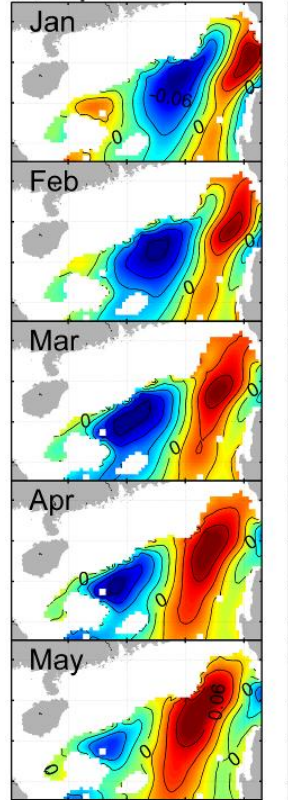

(d) Exp.4
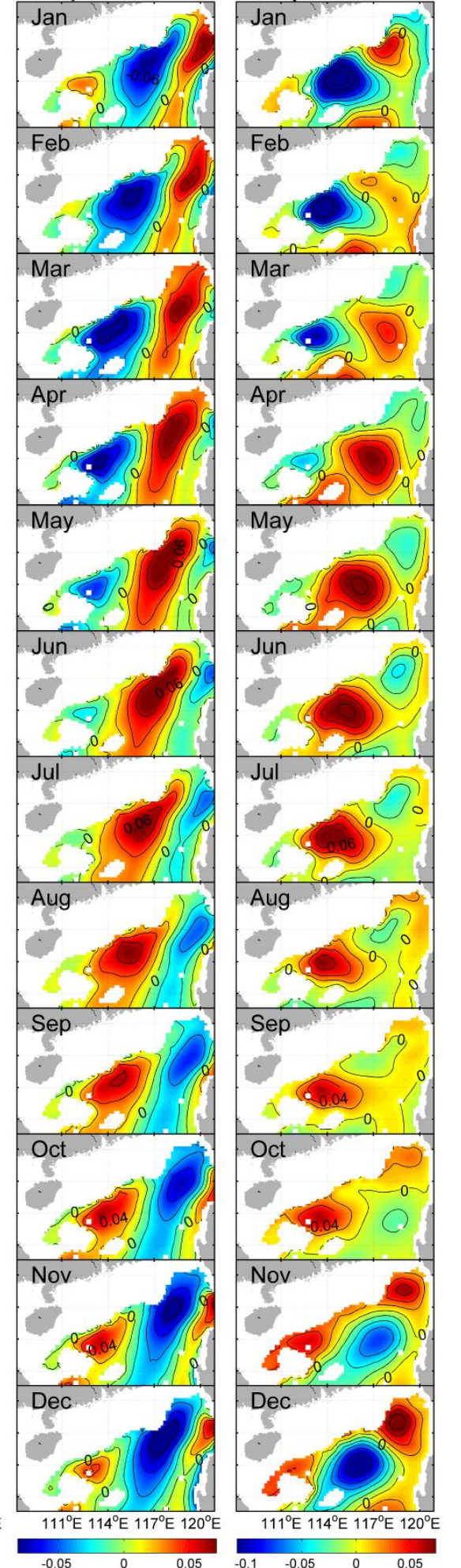

Fig. 12 Monthly potential temperature anomaly (unit: K) at $875 \mathrm{~m}$ in (a) Exp.1 (CI=0.02K), (b)

Exp.2 (CI=0.005K), (c) Exp.3 (CI=0.02K), and (d) Exp.4 (CI=0.02K). 

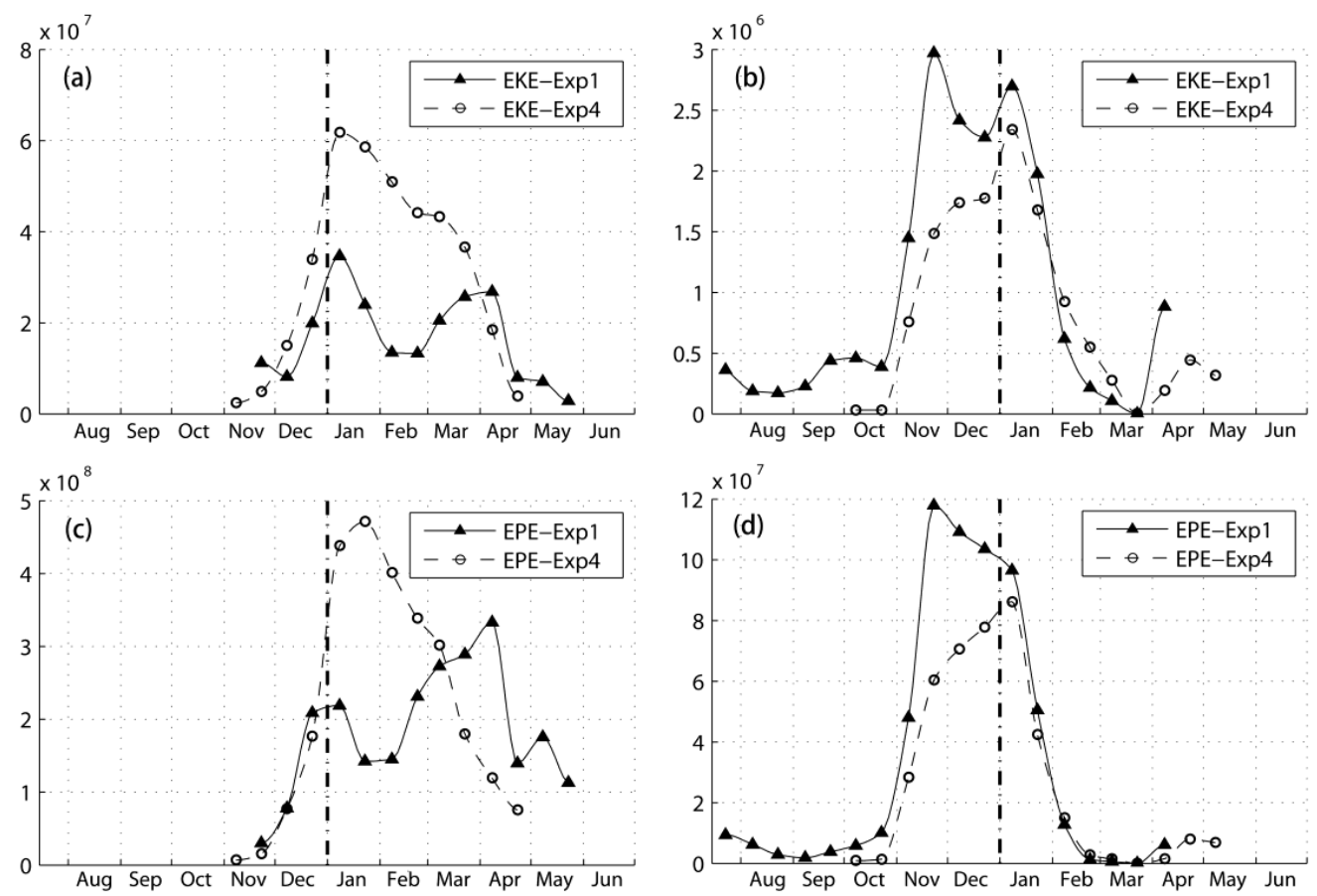

Fig. 13 (a) EKE (unit: $\mathrm{m}^{2 /} \mathrm{s}^{2}$ ) of the LCE at a depth of $118 \mathrm{~m}$. (b) Same as (a) but at a depth of $875 \mathrm{~m}$. (c) EPE (unit: $\mathrm{m}^{2 / \mathrm{s}^{2}}$ ) of the LCE at a depth of $118 \mathrm{~m}$. (d) Same as (c) but at a depth of $875 \mathrm{~m}$. Solid/dashed line with circle/triangles denotes energy in Exp.1/Exp.4. 

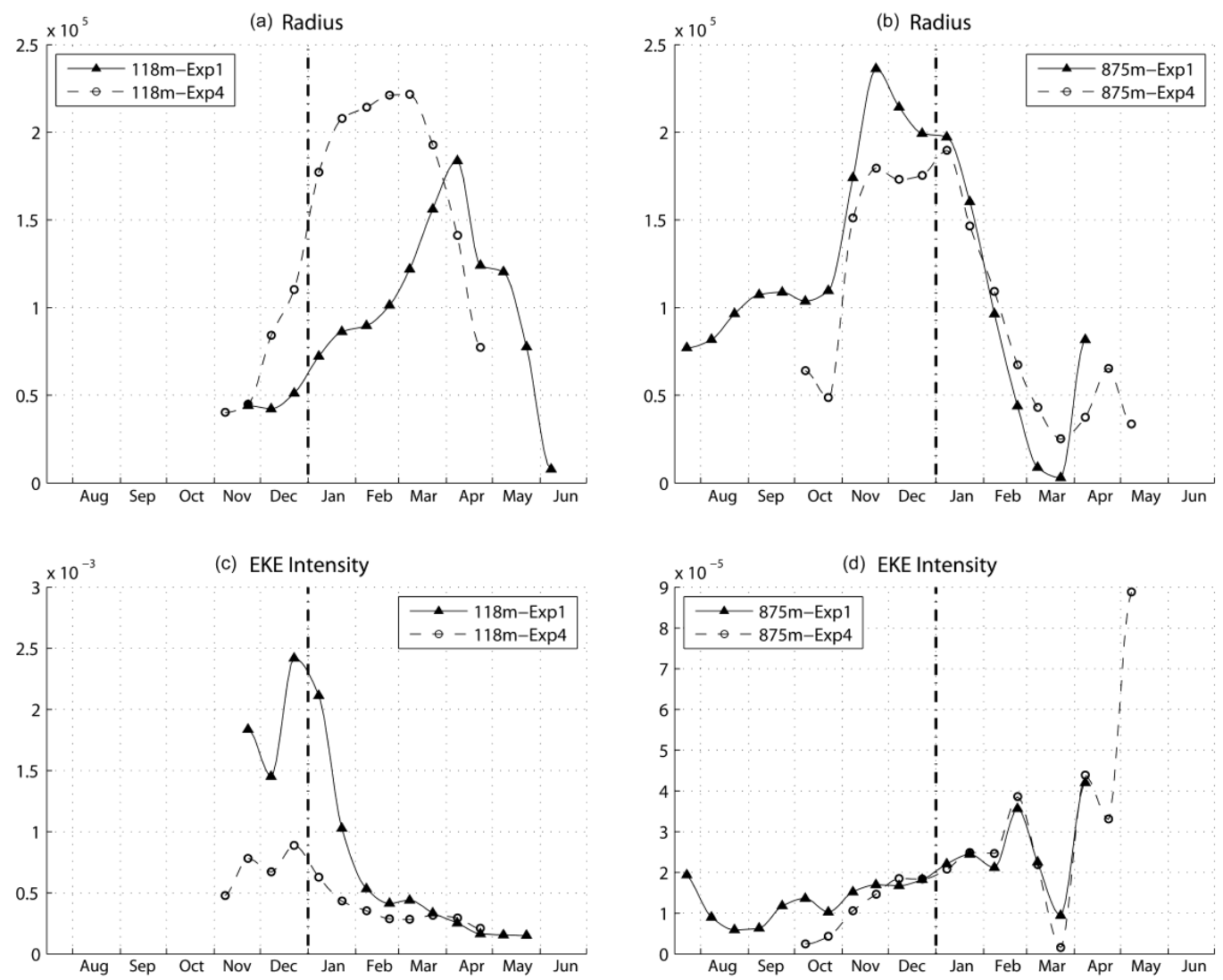

Fig.14 Time series of (a) LCE Radius at 118m depth, (b) LCE Radius at $875 \mathrm{~m}$ depth, (c) LCE EKE intensity at $118 \mathrm{~m}$ depth, and (d) LCE EKE intensity at 875m depth in Exp.1 and Exp.4. 

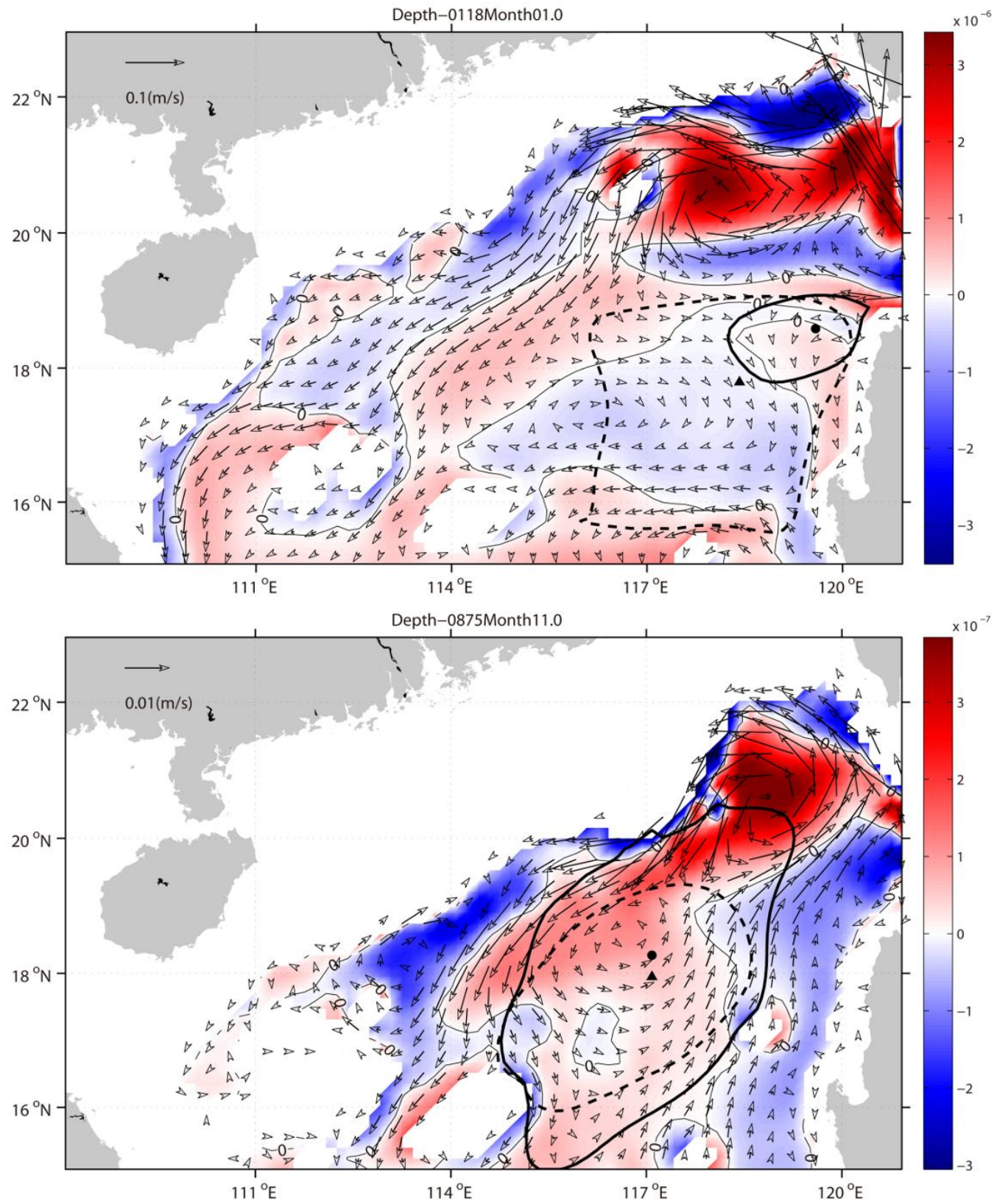

Fig.15 Velocity (arrow) and vorticity (color shaded) difference between Exp.1 and Exp.4 at (a) $118 \mathrm{~m}$ in Januray; (b) $875 \mathrm{~m}$ in November. Black solid (dashed) line denotes the edge of the LCE in Exp.1 (Exp.4). Black dot (triangle) denotes the LCE center in Exp.1 (Exp.4). 

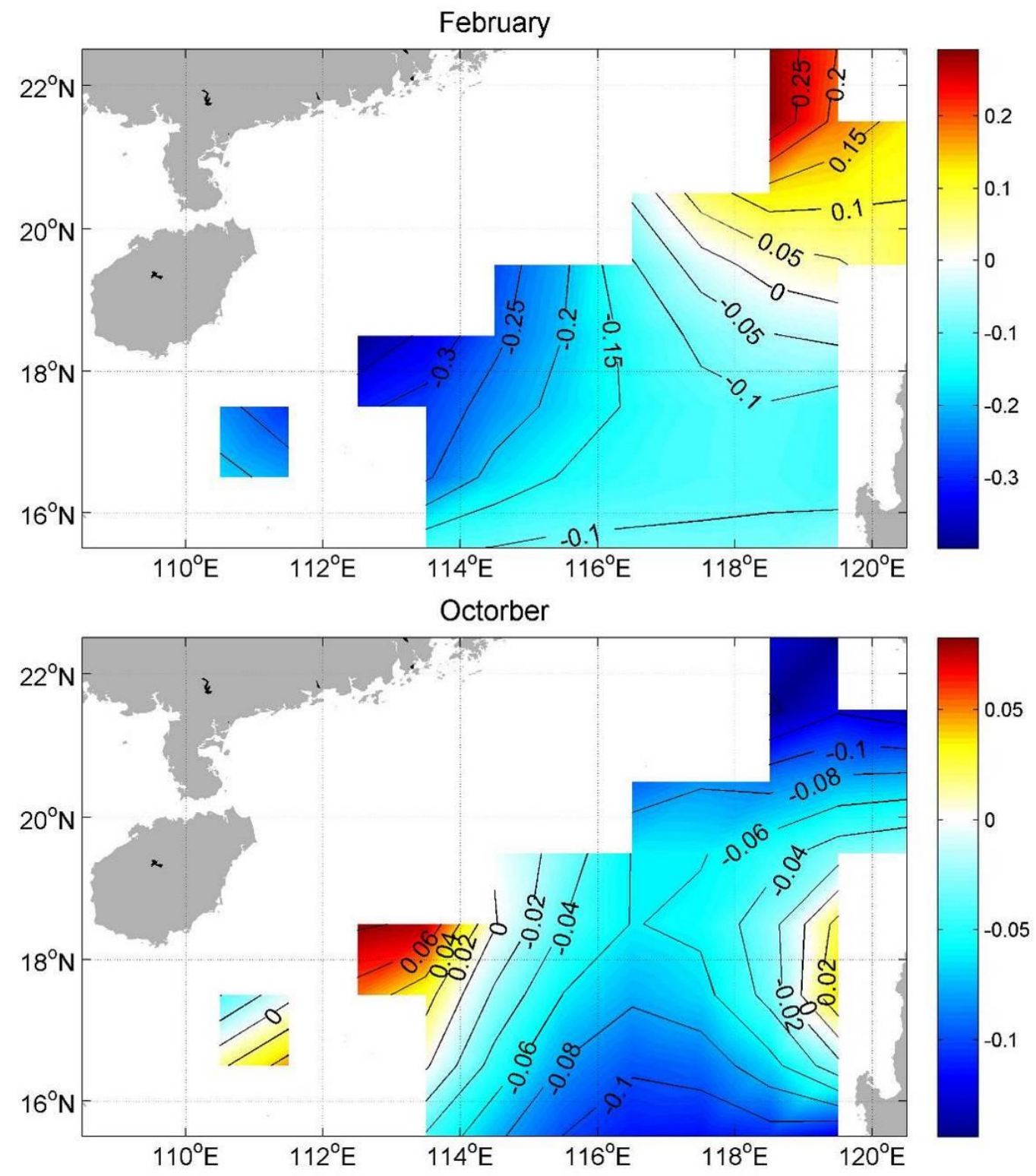

Fig. 16 WOA2009 potential temperature anomaly (unit: K) at 900m in (a) February (CI=0.05K), (b) October $(\mathrm{CI}=0.02 \mathrm{~K})$. 